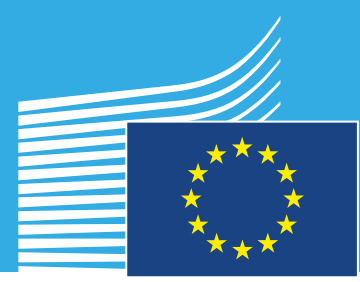

European

Commission

JRC SCIENCE AND POLICY REPORTS

\title{
Global Food Security 2030
}

Assessing trends with a view to guiding future EU policies

Foresight Series

\author{
Albino Maggio \\ Tine Van Criekinge \\ Jean Paul Malingreau \\ 2015
}

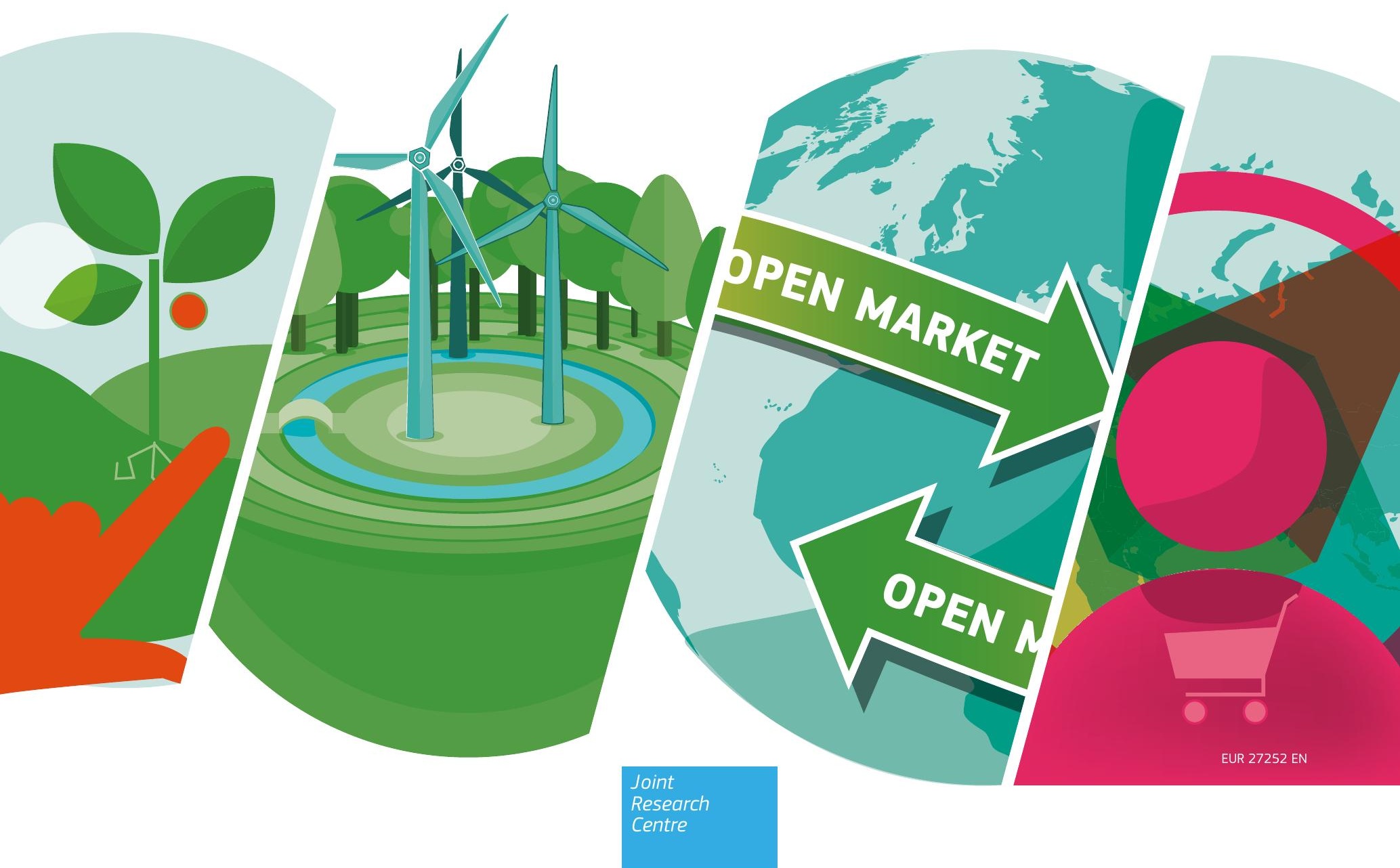




\section{European Commission}

Joint Research Centre

Foresight and Behavioural Insights Unit

Contact information

Joint Research Centre

Rue du Champ de Mars 21, B-1050 Brussels

JRC-DDG-02-FORESIGHT@ec.europa.eu

Tel. +3222958650

https://ec.europa.eu/jrc

\section{Legal Notice}

This publication is a Science and Policy Report by the Joint Research Centre, the European Commission's in-house science service. It aims to provide evidence-based scientific support to the European policy-making process. The scientific output expressed does not imply a policy position of the European Commission. Neither the European Commission nor any person acting on behalf of the Commission is responsible for the use which might be made of this publication.

(C) page 6, Edmund Lowe Photography, \#121249117, 2015. Source: Shutterstock.com

(c) page 8, Federico Rostagno, \#58961845, 2015. Source: Shutterstock.com

(c) page 10, Hung Chung Chih, \#89250022, 2015. Source: Shutterstock.com

(c) page 19, SCOTTCHAN, \#112244876, 2015. Source: Shutterstock.com

(c) page 21, mihaiulia, \#231735844, 2015. Source: Shutterstock.com

(c) page 24, Ververidis Vasilils, \#206244697, 2015. Source: Shutterstock.com

(c) page 25, Tine Van Criekinge, 2015.

(c) page 26, Songquan Deng, \#175463051, 2015. Source: Shutterstock.com

(c) page 28, SOMMAI, \#195794312, 2015. Source: Shutterstock.com

(c) page 31-39, T.W. van Urk, \#72514459, 2015. Source: Shutterstock.com

(c) page 32-34, 1000 Words, \#210043612, 2015. Source: Shutterstock.com

(C) page 32-36, dabldy, \#175718696, 2015. Source: Shutterstock.com

(c) page 32-38, Mario Zappacosta, 2015.

\section{JRC94867}

EUR 27252 EN

ISBN 978-92-79-48364-6 (PDF)

ISBN 978-92-79-48365-3 (print)

ISSN 1831-9424 (online)

ISSN 1018-5593 (print)

doi: $10.2788 / 5992$

Luxembourg: Publications Office of the European Union, 2015

(c) European Union, 2015

Reproduction is authorised provided the source is acknowledged.

Printed in Luxembourg

\section{Abstract}

Despite its multifaceted nature, the debate surrounding food security over the last few decades has largely focused on production and on the challenges facing the agricultural system. Food security has also been directly associated with hunger, poverty and humanitarian aspects. Although agriculture and fisheries are fundamental and essential components of the food system, it is misguided to address the future of food security without looking at the system's many other determinants. The time has come to overcome this conventional approach and to look systemically at food security and its complex nature. The JRC Foresight on Global Food Security 2030 brought together a group of experts and stakeholders to develop a vision for food security in 2030. This vision was then challenged in a test of resilience to unexpected occurrences and/or underestimated trends. The entire process was designed to establish a structured and inclusive discussion that could be useful for guiding future EU policies. This report shows that it is essential for Europe to move towards an integrated examination of a much broader landscape. By 2030 and beyond, food security will increasingly be considered as securing food supply in response to changing and growing global demand. Food security is not only a global and systemic challenge, but also an opportunity for the EU to play a role in innovation, trade, health, wealth generation and geopolitics. Better coordination and coherence at EU level are necessary in order to move from a food-security to a food-systems approach. This report calls for an evolution of present-day policies on food security and beyond into a Common Food Systems Policy in which both the systemic and global dimensions of food security are fully incorporated. 


\title{
JRC SCIENCE AND POLICY REPORTS \\ Global Food Security 2030 Assessing trends with a view to guiding future EU policies
}

Foresight Series

\author{
Albino Maggio \\ Tine Van Criekinge \\ Jean Paul Malingreau
}

2015

European Commission

DG Joint Research Centre 


\section{Acknowledgements}

We would like to thank all the participants of the workshops, steering committee meetings and expert meetings for their valuable time and active support:

Katharina Helming
Jonathan Crush
David Laborde
John Ingram
David Tschirley
Robin Bourgeois
Shirin Elahi
Thierry Kesteloot
Karlheinz Erb
Christian Lauk
Roberta Sonnino
Jo Swinnen
Hannah Pieters
Mario Zappacosta
Christian Habearli
Rogier Schulte
Chiara Tonelli
Richard Tiffin
Howard Leathers
Maria Bruna Zolin
John McClintock
Guilhelme Serodio
Stephen J. Hall
Stineke Onema
Niki Charalampopoulou
Christopher Delgado
Adolfo Brizzi
Shukri Ahmed

\author{
David Hallam \\ Zoe Druilhe \\ David Williams \\ Camilla Toulmin \\ Baba Dioum \\ Christophe Wiese \\ Leonardo Mirone \\ William Vervaeke \\ Ruth Rawling \\ Gianluca Brunori \\ Sirpa Kurppa \\ Jozsef Popp \\ Marianela Fader \\ Adrian Bebb \\ Philipp Aerni \\ Alain Vidal \\ Tian Shi \\ Kepler Euclides Filho \\ Jose Luis Vivero Pol \\ Delphine Deryng \\ Sylvie Brouder \\ Jianru Cao \\ Sebastien Treyer \\ John Roy Porter \\ Alberte Bondeau \\ Ana Moragues Faus \\ Barbara Becker \\ Huajun Tang
}

\author{
Ignacio Perez \\ Marco Acutis \\ Martin Märkl \\ Robert de Graeff \\ John Bensted-Smith \\ Jacques Delince \\ Robert M'Barek \\ Pierre Boulanger \\ Johann Hofherr \\ Neil Hubbard \\ Olivier Leo \\ Jean Pierre Halkin \\ Maria Ketting \\ Raymond Lataste \\ Camilla La Peccerella \\ Vincent Cordonnier \\ Cristina Miranda Gozalvez \\ Jules Seitz \\ Giampiero Genovese \\ Bence Toth \\ Mariusz Legowski \\ Laurence Van Nitsen \\ Martine Godeaux \\ Jyri Ollila \\ Felix Mittmayer \\ Andreas Menidiatis \\ Paola Colombo \\ Hans-Joerg Lutzeyer
}

Acknowledgement and thanks are due to the JRC staff who supported this study and provided key support at different stages and for the four study workshops: Xavier Troussard, Fabiana Scapolo, David Mair, Monica Souza, Anne-Katrin Bock, Laurent Bontoux, loana Profir, Helena Ruiz Fabra, Johanna Trieb, Peter De Smedt, Daniel Bengtsson and Bela Atzel.

Special thanks to Vincent Viaud for his contribution to the Policy chapter and the sections on urbanisation. 


\section{Executive summary}

By 2030 and beyond, food security will increasingly be considered as securing food supply in response to changing and growing global demand. Food security is not only a global and systemic chal-

lenge, but also an opportunity for the EU to play a role in innovation, trade, health, wealth generation and geopolitics. Better coordination and coherence at EU level are necessary in order to move from a food-security to a food-systems approach.

The world is food insecure. Despite important progress, recent estimates indicate that 805 million people were unable to access sufficient food in 2012-2014. Despite its multifaceted nature, the debate surrounding food security over the last few decades has largely focused on production and on the challenges facing the agricultural system. Food security has also been directly associated with hunger, poverty and humanitarian aspects. Somehow, this has generated a conceptual divide between undernourished and nourished people whose problems have been addressed as independent from one another. The time has come to overcome this conventional approach and to look systemically at food security and its complex nature.

The JRC Foresight on Global Food Security 2030 brought together a group of experts and stakeholders to develop a vision for food security in 2030. This vision was then challenged by an extended group of experts in a test of resilience on unexpected occurrences and/or underestimated trends. The entire process was designed to establish a structured and inclusive discussion that could be useful for guiding future EU policies.

Vision 2030 foresees a significant reduction in the relative number of undernourished people and that food security will be guaranteed on a sustainable basis via:

- The significant transformation of agriculture production systems (through investments, research and training);

- Maintenance of an adequate enabling environment in rural areas (rural development);

- A food system where production and consumption are balanced between local, regional and global levels (markets and trade); and

- A largely demand-driven food system where responsible consumer behaviour shapes sustainable objectives.

Current EU food security policies and initiatives are largely in line with the first two key features of the shared vision for food security in 2030. These interventions put smallholder farmers in the most food-insecure regions at the centre of the strategies and rely on the transformation of their activities into competitive and sustainable agribusinesses. This will lead to the achievement of three objectives: 1) ensuring food security; 2) escaping the poverty trap; and 3) fostering the sustainable use of natural resources. Within this approach, global food markets are seen as new and fruitful opportunities for smallholder farming, as long as infrastructure, risk-management mechanisms and information systems are put in place. A special focus on nutrition is maintained and attention is paid to coordination between public and private stakeholders.

Vision 2030 calls for concrete actions to build and promote a more balanced mix between local and global food systems while acknowledging that such systems will become increasingly demand-driven. This will be done through the empowerment of consumers who want better control of the nutritional aspects of what they eat and would like to contribute to sustainability issues worldwide. This trend will be reinforced by rapid urbanisation that will characterise the coming decades, with more than $60 \%$ of the world's population being concentrated in cities of varying sizes. Increasingly, feeding the world will mean feeding the cities. 
Future EU food security policies need to fully consider and address the challenges and opportunities that are likely to arise from such changing demographic and socio-economic trends which will significantly transform future food systems. Current food security policies that focus on targeting those pockets of food insecurity, where hunger and malnourishment persist, will need to be revised. While such policies are certainly worthwhile and commendable, they somehow tend to miss the bigger picture - namely, that food security will increasingly be considered as securing food supply in response to a new and emerging demand. This requires that the extent of these global trends in changing demand, as well as the future role of trade and markets in securing this supply, should be increasingly considered for and integrated into EU food security policy.

Overall, this report shows that while food security has long been considered almost exclusively with respect to hunger, malnutrition and humanitarian questions, it is now essential for Europe to move towards an integrated examination of a much broader landscape. Securing 'regular' access to adequate food for the majority of the 8-9 billion people who will live on earth in the period 2030-2050, while addressing the food insecurity of a fraction of that total, is how a future European food security policy should be approached.

Europe must better exploit the huge opportunity the global food sector represents in terms of innovation, commerce, trade, health, wealth generation and geopolitical relations. To do so, it needs to streamline its policies into addressing the various aspects of global food chains. At the same time, Europe will continue to pay particular attention to the eradication of hunger and malnutrition through special anti-poverty, rural development and food aid actions. Although agriculture and fisheries are fundamental and essential components of the food system, it would be misguided to address the future of food security without looking at the system's many other determinants. In line with this, and as an ultimate goal, this report calls for an evolution of present-day policies on food security and beyond into a Common Food Systems Policy in which both the systemic and global dimensions of food security are fully incorporated. 


\section{Table of Contents}

1. Introduction and rationale 6

1.1 Addressing the global dimension of food security: our approach $\quad 8$

2. Key drivers of change in global food security 9

2.1 Demography 9

2.2 Urbanisation and economic growth 9

2.3 Global food demand and dietary changes 9

2.4 Pressure on natural resources 9

2.4.1 Soil and water $\quad 9$

2.4.2 Energy $\quad 10$

2.4 .3 Biofuels $\quad 10$

2.5 Climate change 10

2.6 Food prices 10

3. The vision: Global Food Security $2030 \quad 11$

3.1 Significant transformation of agricultural and food production systems $\quad 13$

3.1 .1 Sustainable intensification 13

3.1.2 Technology transfer and adaptation 13

3.1.3 Agricultural transformation 13

3.2 An enabling environment in rural areas 15

3.2.1 Rural development strategies 15

3.2.2 Local resilience and social protection 15

3.2.3 Stronger local governance 15

3.3 A balanced food system between local, regional and global levels _........................... 17

3.3.1 Global governance $\quad 17$

3.3.2 Regional governance 17

3.3.3 Trade and markets 18

3.3.4 Transparency, regulation and ethics _.................................................................. 18

3.4 A demand-driven food system 21

4. Policy positioning on global food security 22

4.1 Current policy priorities for food security 22

4.1.1 European food and nutrition security policies 23

4.1.2 European non-development policies impacting global food security _.......................... 23

4.2 Current EU policy positioning on Vision 2030: missing the bigger picture? 23

4.2.1 Uncertainty in trade and markets $\quad 24$

4.2.2 Changing demand and urbanisation $\quad 26$

$4.3 \quad$ Achieving Vision $2030 \quad 27$

5. Key messages and policy recommendations 28

6. Concluding remarks 31

Case Studies 33

What would happen if... international trade in agriculture broke down? $\quad 34$

What would happen if... the world was hyper-urbanised? 36

A future of opportunities for food security through innovation 38 


\section{Introduction and rationale}

Food security has been directly associated with hunger, poverty and humanitarian aspects. Somehow, this has generated a conceptual divide between undernourished and nourished people whose problems have been addressed as independent from one another. Similarly, the tools and instruments used to tackle food insecurity problems have failed to adopt a systematic and coherent approach. Given the future challenges the world will face and the increasing tendency towards complexity and uncertainty, the time has come to move beyond this conventional approach and to look systemically at food security and its complex nature. In this report, we will argue that by 2030 and beyond, food security will increasingly be considered as securing food supply in response to changing and growing global demand. Food security is not only a global and systemic challenge, but also an opportunity for the EU to play a role in innovation, trade, health, wealth generation and geopolitical relations.

Food security is a multi-layered concept, encompassing four key dimensions: the availability of food; physical and economic access to food; its utilisation based on cultural and dietary requirements; and the stability of its provision ${ }^{1}$. Achieving global food security will be one of the most critical challenges in the coming decades. To date, the world has yet to meet international targets for reducing hunger (reduction in the number of hungry people by $50 \%$ and/or halving the proportion of hungry people in the total population) ${ }^{3}$. Despite important progress (209 million less hungry people in the world in 2012-2014 compared to $1990-1992)^{4}$, recent estimates indicate that 805 million people were unable to access sufficient food in 2012-2014) $)^{5}$. Most undernourished people (791 million) live in developing countries. In some of these (sub-Saharan Africa), there has even been an increase in the absolute number of chronically hungry people reported (from 176 million in 1990-1992 to 214 million in 2012-2014). There are also major differences in hunger trends across regions that can be attributed to various constraints associated with political, social, economic and environmental variables and their interactions.

Despite its multifaceted nature, discussions about food security in the last few decades have largely focused on agricultural production and its associated main challenges for the agricultural system. It has also been directly linked to hunger, poverty and humanitarian aspects. There is a sound rationale for this:

- Due to the growing population, it is estimated that the demand for food will increase by $50 \%$ by 2030 compared to current needs $s^{6}$ and by $80-100 \%$ in $2050 ;$

- The vast majority of hungry people currently live in rural areas;

- Further expansion of agricultural land will be limited;

- Climate change may adversely affect areas that already suffer from unpredictable weather and unfavourable conditions for cultivation; ${ }^{8}$

- An increasing demand for food requiring a high energy input (e.g. animal-based products) could add further pressure to the sustainability ${ }^{9}$ of production systems. ${ }^{10}$

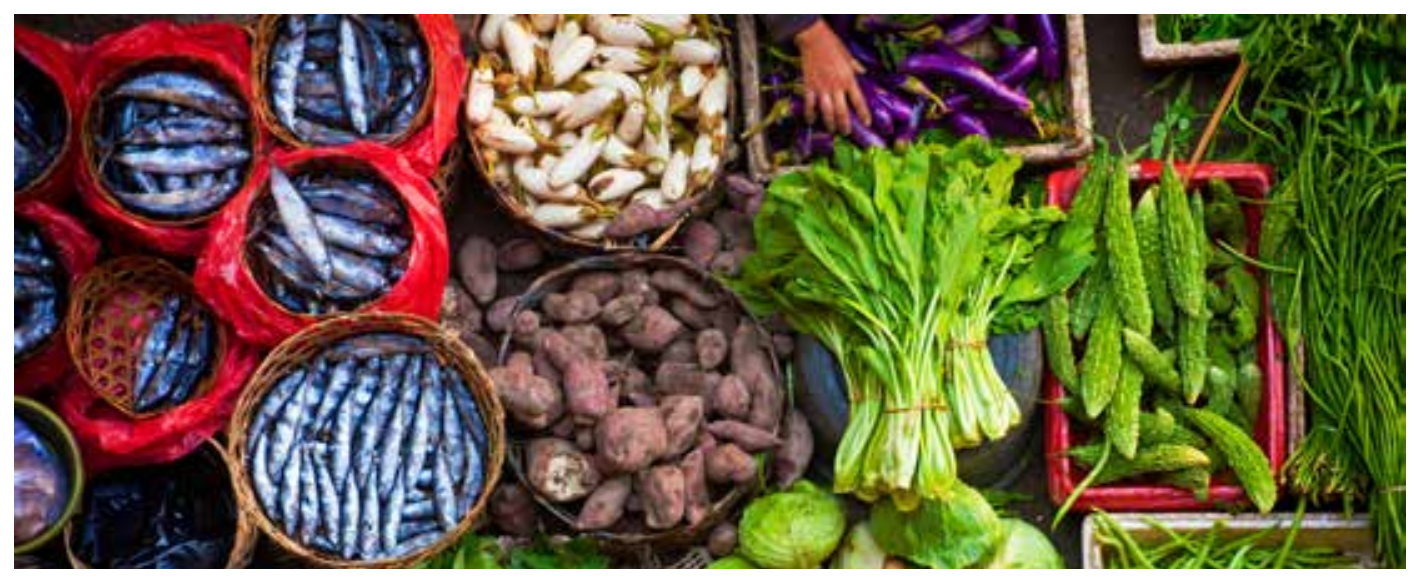


In some cases, constraints on food security in rural areas may not be directly related to food production per se but to other barriers that affect poverty, such as the lack of decent infrastructure, ${ }^{11}$ which may physically isolate rural communities, and/or poor communication/information tools that may practically exclude farmers from the market. ${ }^{12}$ In other cases, sanitation and the resulting health problems may adversely affect people's physical condition, ${ }^{13}$ meaning they lack the strength to work and earn money to buy and/ or produce food for themselves, their families, and their communities. Within this context, over the last decade, meta-analyses, experimental work and expert consultations have all contributed to defining ways towards the sustainable intensification of agriculture. ${ }^{14}$ A particular focus has been on African agriculture, ${ }^{15}$ and on those areas where the need is more urgent and the production gap is, in principle, easier to fill. ${ }^{16}$ Most outcomes from these studies, implemented through rural development programmes funded by industrialised countries, the European Union $(E U)^{17}$ as well as private ${ }^{18}$ and international ${ }^{19}$ organisations have resulted in several success stories. The merit of this work has been that it has laid the foundations for addressing food security, sustainability and their interrelationship, not as separate issues but as part of a food system. Today's "food equation"20 attempts to reset the balance between food security in supply, social equity, consumer demand, economic and environmental sustainability.

More recently, systems analysis on food security has scaled up the discussion; instead of looking at the individual components of the food system, it approaches the topic from a more holistic vision, addressing both obvious and less-obvious relationships between different stages and actors across the food chain. This is critical in a multi-component and interconnected system, such as that governing food supply, availability and access. By focusing on individual components, inter-linkages and cross-cutting issues can be easily overlooked. Leverage points/strategies that may have structural effects on the system as a whole can be missed.

Scenario analyses have been used to address the systemic and dynamic nature of food security. These are generally based on the identification of drivers and constraints that, in a given system, could lead to possible futures, which are also known as alternative worlds. In contrast to extrapolation and trend analyses, which tend to look at a predetermined future, scenarios shape and observe possible future outcomes and discuss alternative development paths which lead to such outcomes. Several excellent analyses have been based on this approach. In addition to Foresight: The Future of Food and Farming, ${ }^{21}$ which has set out a broad framework for discussion, two more formal foresight exercises, among others, have presented and detailed alternative futures for the food system.

In Agrimonde, 22 a global orchestration scenario was compared to a technogarden scenario. The first scenario describes a system based on supranational institutional governance able to deal well with major challenges (in this case, climate change) yet vulnerable to unexpected events or regional changes. Here, the assumption is that economic growth will feed the world, in a context in which environmental protection is not a priority. In contrast, the techno-garden scenario is a technology-driven globally connected world, which relies on large-scale human-made solutions for the ecological intensification of production and a reduction in current inequalities as regards consumption (reducing under-nutrition in some regions, while cutting waste and excessive food consumption in others). In this case, the objective is to feed the world while preserving its ecosystems. Similarly, the Standing Committee for Agricultural Research (SCAR) $3^{\text {rd }}$ Foresight Exercise ${ }^{23}$ proposed a productivity narrative that in some way resembles Agrimonde's global orchestration scenario and a sufficiency narrative which focused on the need to mitigate demand through a radical behavioural change in order to stay within and preserve the capacity of "system Earth".

A few other exercises of this kind with a more European focus include Ground for choices, ${ }^{24}$ UNEP Global Environment Outlook $3,{ }^{25}$ Advanced Terrestrial Ecosystem Analysis and Modelling (ATEAM), ${ }^{26}$ Millennium Ecosystem Assessment, ${ }^{27}$ European Land- use Scenarios (EUruralis), ${ }^{28}$ EEA Land-use Scenarios (PRELUDE) ${ }^{29}$ and the SCAR Foresight Exercise $2 .^{30}$ These studies all focus mainly on rural environment and agriculture in general and, in some cases, on market aspects.

Scenario-based approaches can help with mapping, navigating complexity and establishing common platforms to discuss and integrate different views. ${ }^{31}$ Describing (and using) alternative, equally plausible futures opens up the opportunity for more policy options and actions. This is somewhat in contrast with the need for prioritisation, a process that is much needed in policy-making. Moreover, the scenarios are generally built on drivers (generally two) that do not sufficiently describe the multidimensional nature of food security and, in the worst case scenario, could even be misleading. For example, while most studies consider climate change as one of the key constraints on food security, most scientific evidence indicates that climate change is likely to have a neutral or even a relatively modest positive effect on agricultural production globally at least until $2050 .{ }^{32}$

It is against this background that in mid-2012 the European Commission's Joint Research Centre (JRC) started work on a foresight study on Global Food Security 2030. The aim of this study was to explore potential developments that will significantly affect the world food situation in 2030 in order to identify the most crucial areas for EU policy intervention. Thus, the question we set out to address in this study was: "What should the EU do to contribute to meeting the major food security challenges the world will face by 2030?" The aim of this work was to go beyond the identification of macro challenges, which have already been identified in similar exercises, and to identify instead new areas of intervention in which policies could most effectively advance food security. 


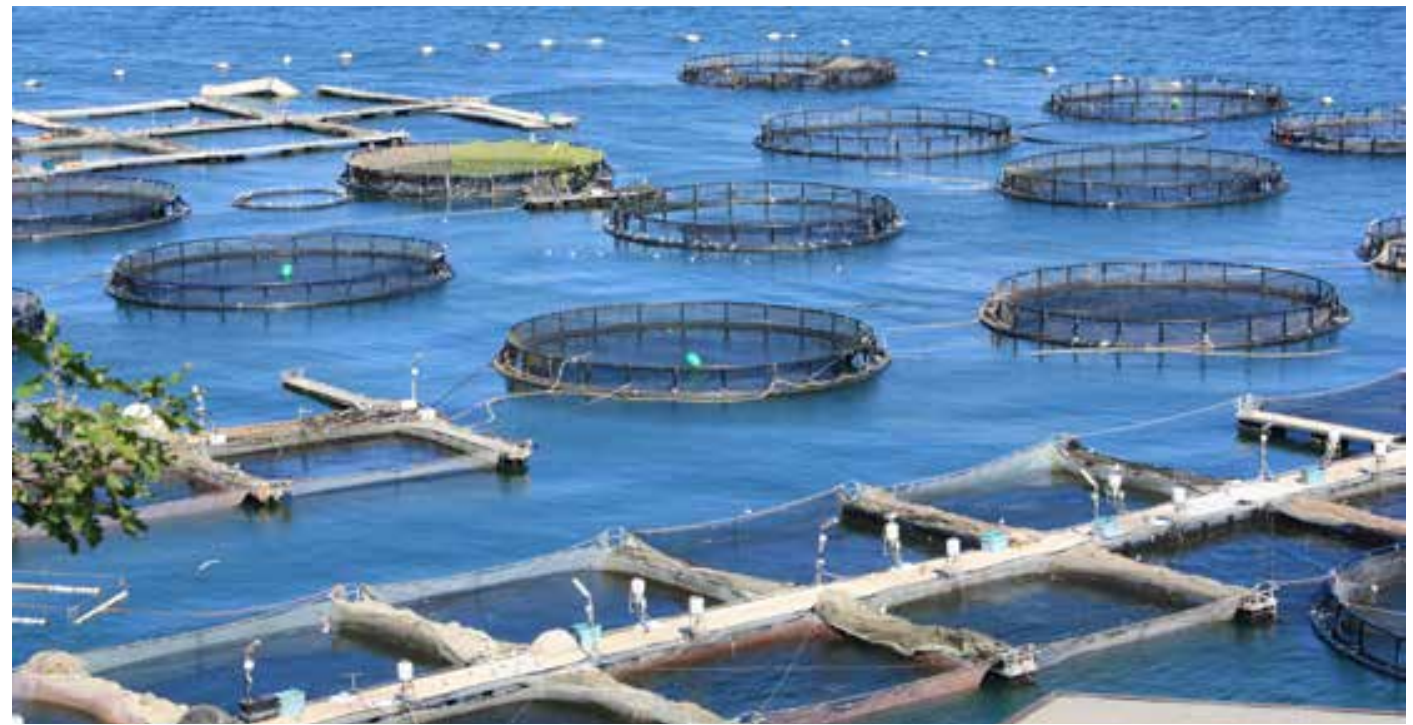

\subsection{Addressing the global dimension of food security: our approach}

The multidimensional nature of the global food system has already been satisfactorily documented so we deliberately decided not to reiterate the descriptive 'all-encompassing' process. Instead, the starting point of this study is the observation that, in terms of informing future policies, there are benefits to be derived from identifying key areas of concern. Therefore, the objective is to identify possible priorities among all those issues that will arise if a population of 8.5 billion people is to live in a food-secure world in 2030 (or even 9.5 billion in 2050). We rationalised that such a selective process could help keep the focus on key issues and identify early steps that could be taken today to contribute significantly to food security in the future.

With reference to the time horizon considered in this foresight study, the following periods can be defined:

- From the present to 2020: the global food security drivers are essentially set out and recognised as regards needs, overall trends and constraints in food availability. The focus is on immediate policies.

Fig. 1: Structure of the foresight process
- From 2020 to 2030: food demand will increase significantly and novel response strategies (e.g. in terms of technologies, investments, trade, etc.) will emerge. Long-term policy goals should be set.

- From 2030 to 2050: world population growth rate is expected to stabilise as the maximum population has almost been reached (although these estimates have been questioned recently). ${ }^{33}$ The focus is more on fundamental variables such as technologies, resources and new social models. New development paths can be constructed.

In line with the overall principle of identifying steps that must be taken today to contribute significantly to improving food security through alternative paths for development, 2030 was chosen as a functional time frame and target for our analysis.
The foresight study was designed around the following principles and thought processes:

1. Envision the future of food systems in a structured and constructive way;

2. Agree on the most crucial drivers of change affecting food security in the future;

3. Reach a consensus on the most likely vision for 2030;

4. Challenge this vision by investigating three drivers which could pose major challenges;

5. Analyse current policies and policy needs in terms of responsiveness, flexibility and resilience to food security needs and future challenges.

Four interactive workshops involving over 100 experts from across various disciplines and affiliations, and individual expert consultations were organised (Figure 1). The results of this process are presented below.

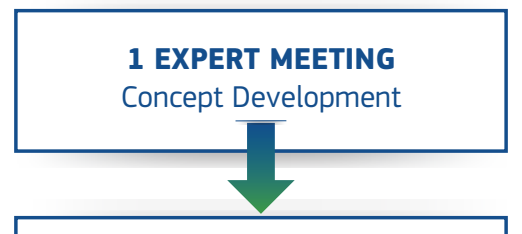

3 THEMATIC WORSHOPS

Vision Development
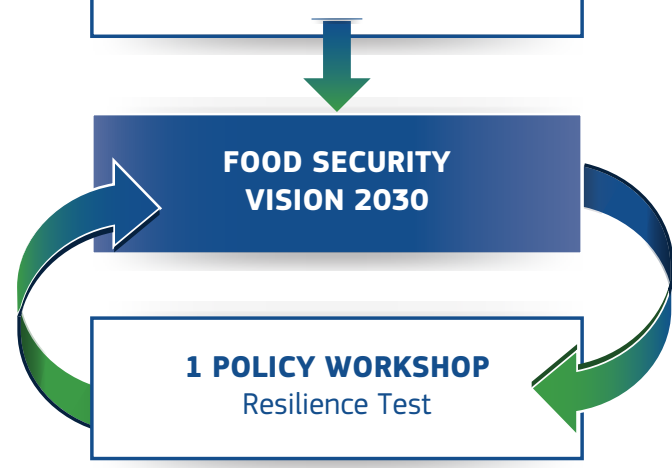


\section{Key drivers of change in global food security}

\subsection{Demography}

The United Nations foresees that the world population will grow at an annual rate of $0.96 \%$ from now until 2030 and at a rate of $0.63 \%$ per year between 2030 and 2050 . Today's population of about 7 billion will rise to approximately 8 billion by 2030 and to over 9 billion by $2050 .{ }^{34}$ Based on these estimates, the world will have to feed an extra 1.62 billion by 2030 and an additional 2.38 billion people by 2050. Those figures may change with social, economic and political determinants but not very significantly. ${ }^{35}$ Population growth will mostly occur in low-income/developing countries, with Africa expected to double its population from 1 to 2 billion by $20500^{36}$

\subsection{Urbanisation and economic growth}

The world's urban population is expected to grow much faster than the rural population, and by 2050 more than $65 \%$ of the population is expected to be living in urban areas. Urbanisation will mainly occur in low-income countries. In 2025, more than 10 million people will inhabit five new megacities in Asia. ${ }^{37}$ Urbanisation and economic growth will occur in unison. The Organisation for Economic Co-operation and Development (OECD) and the United States Department of Agriculture expect that beyond 2013 world economic growth will be around $3 \%$ while the average annual growth for developing countries is expected to be around $5 \%$ per year. This growth will be a major driving force behind future demand for food.

\subsection{Global food demand and dietary changes}

A growing global population along with rising incomes will increase the global demand for food and agricultural products by $50 \%$ in $2030^{38}$ and possibly by $60 \%-110 \%$ in $2050 .{ }^{39}$ Based on the UN's Food and Agriculture Organization (FAO) figures, agriculture production in developing countries would need to double.

Dietary changes associated with population growth, urbanisation and higher incomes will have a significant impact on the food system. Production of some food items, such as meat, fresh produce and processed products will require more resources than staple crops such as wheat and rice. The growing demand for meat has been predicted to rise in high-income countries from 37 to $52 \mathrm{~kg} /$ person/year and in low-income countries from 26 to $44 \mathrm{~kg}$ between now and $2050 .{ }^{40}$ More significantly, the consumption of dairy products in developing countries is also expected to increase by $70 \%$ from 2000 to $2050 .{ }^{41}$ This trend will put significant pressure on global food availability since a growing share of cereals and oilseed (in general, around $8 \mathrm{~kg}$ of grain is required to produce $1 \mathrm{~kg}$ of meat) ${ }^{42}$ will be used to feed animals away from more direct food chains. Current yield trends are insufficient to cope with these needs. Crop production will need to double by 2050 if the whole world follows the current diets in developed countries.

\subsection{Pressure on natural resources}

\subsubsection{Soil and water}

Cropping area (approximately 1400-1600 million hectares (ha) of the 4600 available for agricultural activities) has marginally increased (by $8 \%$ ) over the past 30 years. As a consequence, the available cropland per person has decreased from over 0.40 ha in the 1960 s to below 0.25 ha today. Estimates indicate that by 2050 the total area of arable land available can only be expanded by $4.3 \%$. Developing countries will cultivate approximately 107 million ha more but will face a 38 million ha reduction in arable land. ${ }^{43}$ Urbanisation, inadequate soil and water management practices that lead to loss of fertility, salinisation and erosion are the main drivers of land degradation. It is estimated that each year around 10 million ha of cropland are lost through soil erosion ${ }^{44}$ while another 10 million ha are abandoned due to the irrigation-dependent phenomena of salinisation and alkalinisation. ${ }^{45}$

Agriculture uses approximately $70 \%$ of the fresh water globally consumed by humans, with even higher percentages in dry regions. The demand for water will compete critically with other uses mainly linked to expanding urbanisation and industry. In some countries, harvests have already experienced significant reductions due to falling water tables. Poor water management in agriculture also leads to greater salinisation (globally, more than 800 million ha are salt-affected) ${ }^{46}$ and aggravated land degradation. Of all the biotic and abiotic stresses, drought $^{47}$ and salinisation ${ }^{48}$ account for the greatest yield reductions in agriculture. As a consequence of the scarcity of resources, such as land and water, and with 
the availability of capital, new forms of land ownership, tenure and management will evolve. Some will favour the injection of productive capital in agriculture, while others may lead to food appropriation rather than providing potential benefits for local farming communities. ${ }^{49}$

\subsubsection{Energy}

The FAO estimates that yields will continue to grow in the future ( $0.8 \%$ per year), but at a slower pace compared to previous decades ( $1.7 \%$ per year) due to rising production costs and lower investments in research and development (R\&D)..$^{50}$ Production costs depend on the price of inputs such as fertilisers, machinery, pesticides and other chemicals, which are all closely related to oil prices. As oil prices rise, so will the cost of agricultural inputs, although the reverse is also true. Thus, oil and energy prices are inversely linked to agricultural production costs. The International Food Policy Research Institute (IFPRI) estimates that, given a $100 \%$ increase in oil prices, the number of malnourished children would increase in all regions compared to the baseline scenario. ${ }^{51}$ Higher fertiliser prices and greater demand for crop-based feedstock will raise the price of all agricultural commodities. These higher prices, combined with lower cereal production resulting from higher production costs, will create a worse food security situation.

\subsubsection{Biofuels}

The demand for bioenergy, in particular biofuels, can be expected to grow along with an increasing demand for energy products and rising oil prices. Developing alternative fuels from organic sources has provoked intense debate since it involves redirecting crops like maize, sugar cane and oilseed from the food to the biofuels production chain. It is expected that between 2013 and 2022, global ethanol and biodiesel production will grow at an annual rate of $4.3 \%$ and $3.4 \%$, respectively. ${ }^{52}$ In the short term, food security will not be affected by the expansion of energy crops, which may actually benefit the economy in some rural settings. However, there are concerns about the use of other cereals (normally used for food) for the production of biofuels and their effect on indirect land-use changes and the economic sustainability of the entire chain, which thus far has been supported by governments. It is not clear how and to what extent biofuels will affect global food prices and thus global food security. However, development of second-generation biofuels and the smart use of land (including marginal land) for energy crops will certainly contribute to the redesign of a renewed food system that makes more sustainable use of both agricultural inputs and natural resources and does not compete 'unduly' with food production.

\subsection{Climate change}

Agriculture activities have a dual link with the climate. Seasonal weather conditions affect plant growth and production both positively and negatively and impact food security at all levels; some areas may benefit from climate change while others will suffer. Therefore, changes in weather patterns may exacerbate crop-yield differences between regions and countries. In turn, agricultural activities, including land conversion, are a source of greenhouse gas (GHG) emissions, which currently account for $10-12 \%$ of total global anthropogenic emissions. A shifting climate could lead to population migration which will alter the pattern of supply and demand for food. Under a moderate climate change scenario, it is expected that future weather anomalies will lead to the annual displacement of over 12 million people by the end of the $21^{\text {st }}$ century. ${ }^{53}$ While climate change is an important driver for food security, in this study we have not considered it as the main driver for agricultural production by 2030 .

\subsection{Food prices}

Poor people spend a large part of their income on food, and even more so when prices are high. About half of the malnourished people in the world are small farmers while another $20 \%$ are rural-wage labourers who often work on other farms. Thus, with many poor and food-insecure people being affected as both consumer and producer, the effects of price changes on food security are complex and heterogeneous across households, regions and countries. For decades, the 'common wisdom' was that low prices for food and agricultural products were an important cause of poverty and food insecurity in developing countries. The 2007-2008 food price crisis triggered a major turnaround in perspective: high food prices are now considered to be the cause of hunger and poverty. To understand the impact of food prices on poverty and food insecurity, it is necessary to distinguish between net food sellers and net food buyers, and between exporting and importing countries. A household is classified as a net food seller when the value of its food production is higher than the value of its food consumption. The reverse is true for net food buyers. The policy debate has not always taken the complexity of these effects into account. ${ }^{54}$

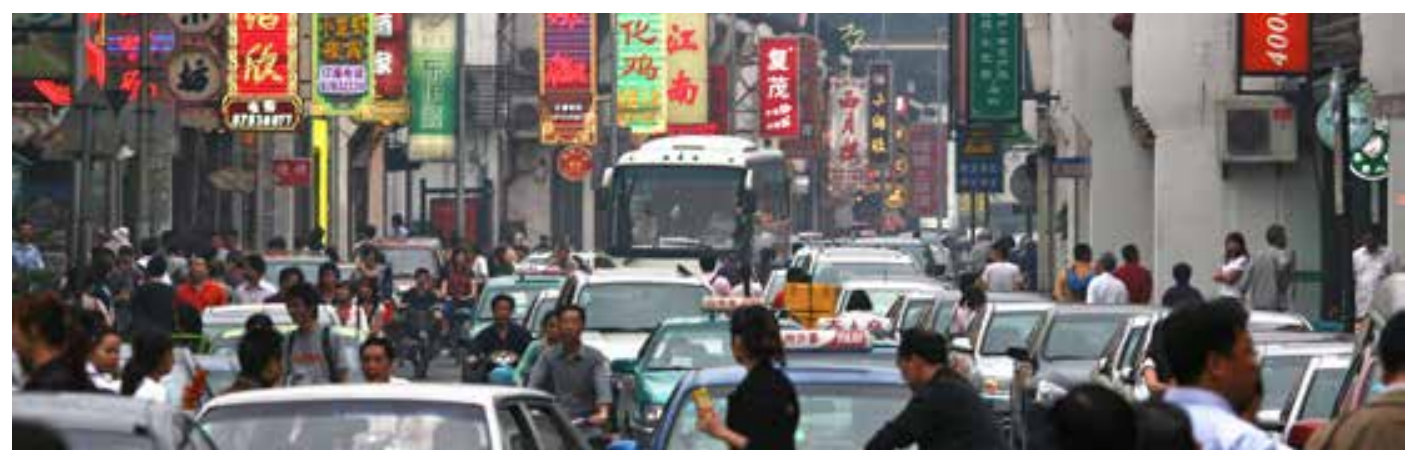




\section{The vision: Global Food Security 2030}

By examining and agreeing upon the key drivers of change a vision was developed for global food security by 2030 . The key challenges to actually reaching this vision were then defined. This, in turn, led to the identification of priority areas that could guide policy-makers in the design and implementation of appropriate policy changes. In a foresight process, agreeing on a vision (i.e. where we will/ want to be) is often a useful way to identify key needs, milestones or a structured roadmap to achieve that vision. Although a vision has to be plausible and therefore based on statistical trends and sound facts, its aspirational nature is essential to engaging stakeholders in a visionary approach to successfully achieving and shaping a specific future. Based on experts' knowledge and understanding of future developments, setting out the best future ahead of us (i.e. a rosy vision) will be instrumental in exploring the path we have to take, testing its feasibility, identifying any constraints and fine-tuning a roadmap.

By 2030 , the overall world economy has continued to grow and benefits are shared more equitably across the globe. This has proved critical in reducing the number of people living in extreme poverty to 100 million. Consistent with projections, world population is now at 8.3 billion and demand for nutritious food, which has grown by $40 \%$, is still only partially satisfied. Malnutrition persists in scattered patterns across the globe, although there has been a significant reduction in the relative number of undernourished people. This achievement in addressing under-nutrition worldwide was made possible thanks primarily to an increase in agricultural productivity in African and South Asian regions through coordinated international public and private investments.
Trends towards geopolitical stability and the need to cooperate on global resource management have ushered in a new era of political and economic collaboration at the global level. Multilateral institutions are key players now in maintaining order through advances in global governance, while at the domestic and regional level political reform has favoured emerging markets, enabling them to play a crucial role in creating a more equitable economic and political order.

Continuing focus on the resilience of the most food-insecure regions in the world, and increased investments targeting nutrition deficiencies in children under five have been key in reducing major food insecurities worldwide. Access to potable water for rural and urban populations is widely ensured (overcoming the problems regarding degradation of water quality, access, waste and the regional imbalance). Fish and fish-derived products play a key role in improving the proteinic component of diets. The application of sustainable fish farming and effective fisheries management systems ensures the sustainable exploitation of renewable natural resources from the oceans and inland waters, such as fish, bivalves and algae. Fisheries and aquaculture are contributing substantially to providing food of high nutritive value for healthy diets. ${ }^{55} \mathrm{In}$ 2030, over $60 \%$ of fish for direct human consumption is supplied by aquaculture. ${ }^{56}$ [In 2015, $99.7 \%$ of food (calories) comes from the land and less than $0.3 \%$ from the oceans and aquatic ecosystems. However, fish still only provides $22 \%$ of the protein intake in sub-Saharan Africa. The proportion of dietary protein that comes from fish is extremely high in Senegal (47 \%), Gambia (62 \%), and Sierra Leone and Ghana (63 \%).]

\section{Global Food Security Vision 2030}

A world where food security is guaranteed for all on a sustainable base via:

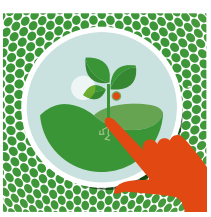

The significant transformation of agriculture production systems (through investments, research and training);

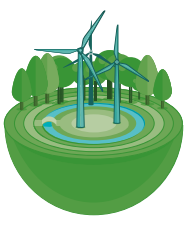

The maintenance of an adequate enabling environment in all rural areas (rural development)

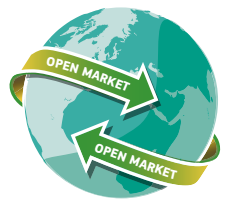

A food system where production and consumption are balanced between local, regional and global levels (markets and trade);

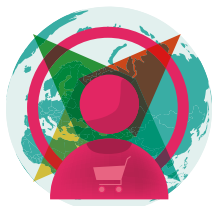

A largely demand-driven food system where responsible consumer behaviour shapes sustainable objectives. 


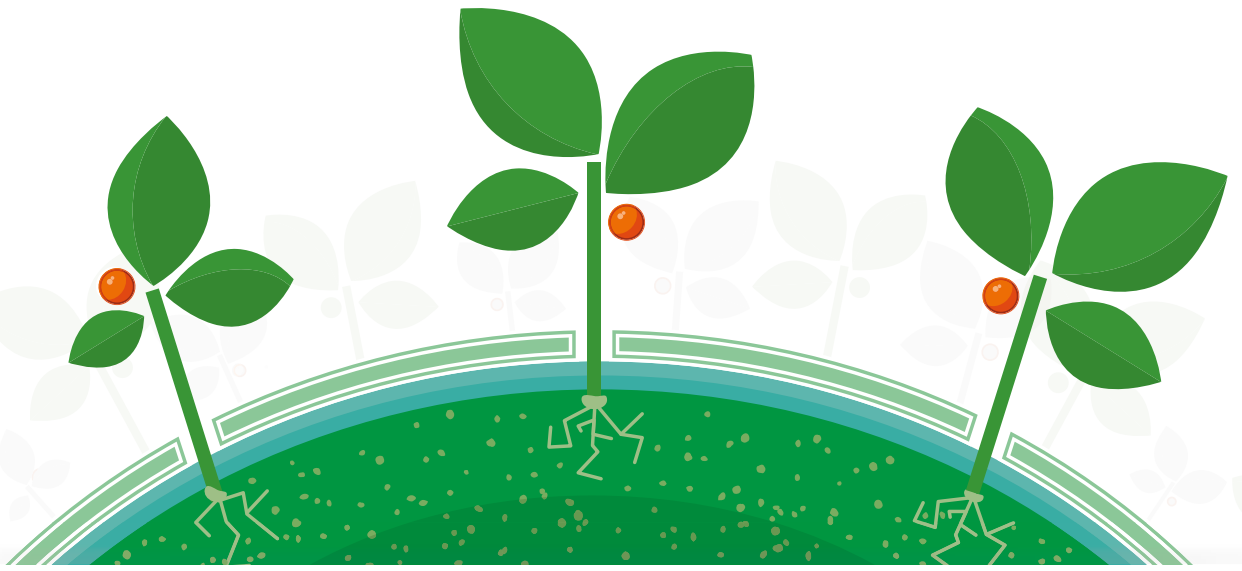

A significant transformation of agriculture and food-production systems

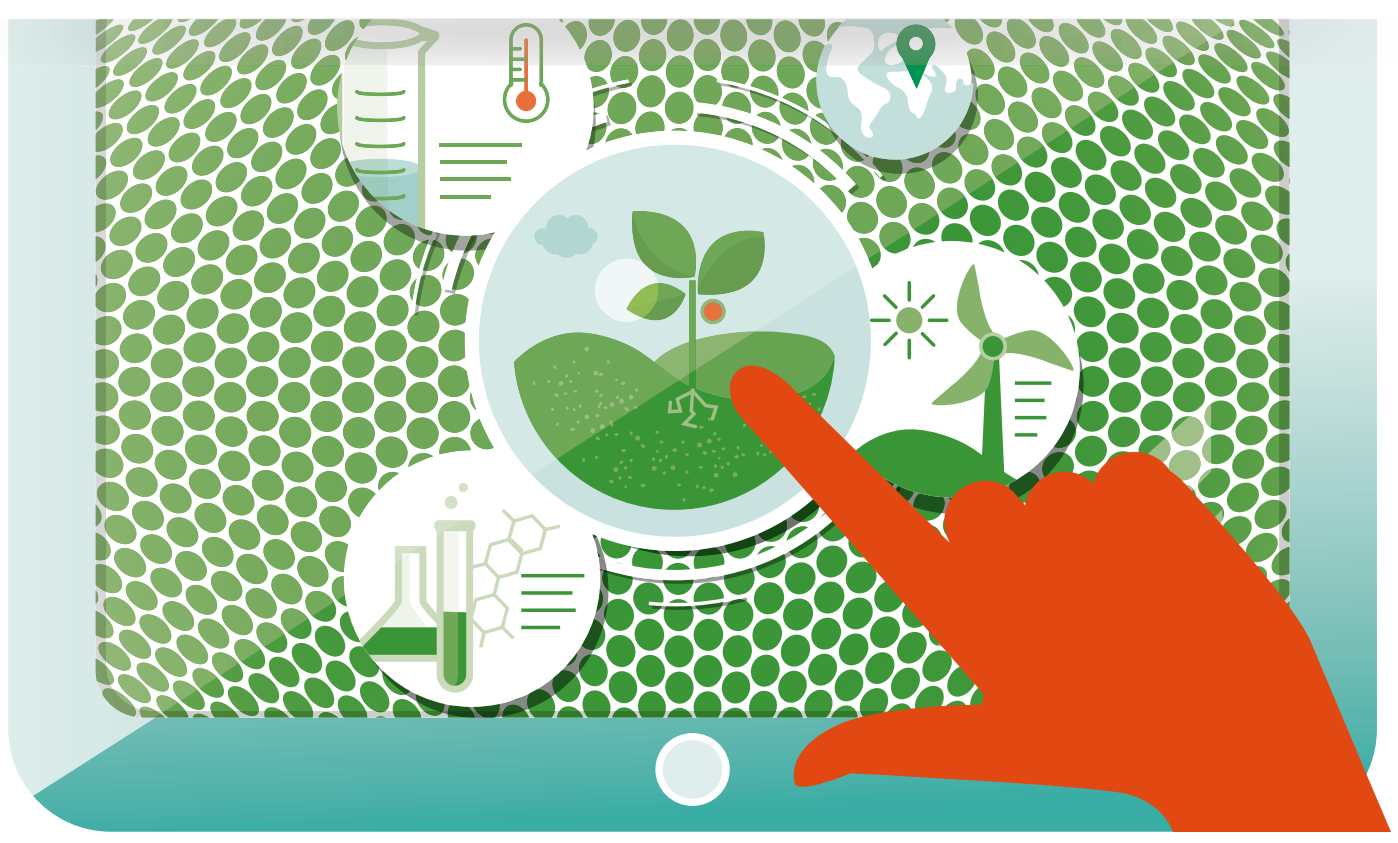




\subsection{Significant transformation of agricultural and food-production systems}

In 2030, the world has witnessed a significant increase in agricultural productivity in those farming systems that were performing far below their potential. In both industrialised and developing countries, a more efficient and sustainable use of natural resources has been achieved. In the former, this is mainly as a result of a more efficient use of agricultural inputs, a determined effort in waste reduction (e.g. through precision farming), new farming practices and genetic improvements in crops. In developing countries, improvements towards a more sustainable use of fundamental inputs (water and fertilisers), adoption of soil and water conservation/management principles, and a reduction in post-harvest losses have been critical in making agriculture more productive and more sustainable. Aquaculture has also developed on the principles of sustainability and now provides an important source of animal protein. This transition has accompanied a shared understanding that a purely economic-growth perspective needed to co-evolve with multisectorial sustainable development and natural resource conservation.

\subsubsection{Sustainable intensification}

In developing countries, agricultural systems have evolved significantly and yield gaps in major staple crops have been considerably reduced. Sustainable intensification has been strategically applied to under-yielding countries (Africa, Southern Asia), mainly via knowledge transfers and information sharing on best practices, technology transfer, adaptation to environmental specificities and increased support for local extension services. This strategic intensification has important social and environmental impacts, with an improvement in the self-sufficiency of local smallholder farmers to cover their basic nutritional needs and the possibility to trade a larger agricultural production surplus to access other sources of food for their remaining nutritional needs. It has also reduced GHG emissions and prevented major biodiversity losses, which would otherwise have been increased by alternative solutions (e.g. land clearing). The sustainable management and use of water, soil and fertilisers have become the foundations of sustainable intensification.

\subsubsection{Technology transfer and adaptation}

Adaptation of agricultural research and technology to local needs has been an important determinant in enhancing global food security and making agricultural systems more resilient. The introduction of breeding programmes and biotechnology solutions to improve the resistance of local crops to environmental stresses - including drought, salinisation, high temperatures and pests - has been pivotal in this context. Schemes promoting resilient agriculture practices have been put in place in most developing countries, including various forms of mixed cropping for a more effective use/recycling of nutrients (e.g. intercropping, rotations, green manuring, etc), integrated/intensive crop-livestock systems, soil conservation practices (e.g. minimum or zero tillage), and the optimal application of fertilisers and herbicides (micro-dosage associated with localised applications). Water-saving agriculture techniques have been extended, and previously untapped water has been made available for agriculture in Africa and Southern Asia. Post-harvest losses have been reduced thanks to the implementation of cheap technologies that are accessible to farmers. Non-food crops, such as energy crops, have created opportunities to increase farm income, especially since second-generation biofuels now rely on crops raised on marginal land and are no longer in competition with main food production.

Adaptation to resource scarcity and population growth has also taken place at food distribution and utilisation (household) levels with a progressive adaptation of dietary demands. A reduction in food waste and over-consumption are a consequence of significant behavioural changes more respectful of environmental, ethical and safe dietary principles.

\subsubsection{Agricultural transformation}

In developing countries, the landscape of food-production systems has changed significantly thanks not only to the adoption of new agricultural-related technologies but also to the transformation of agricultural business models, which have become more profitable, competitive and connected to local, regional and even global food markets. Overall, agriculture is increasingly being considered as a very viable income-and wealth-generating business opportunity. This transformation has been fostered by the introduction of new types of partnerships between public organisations, the private sector, research centres and farmers' organisations, which have helped to optimise investments. Private-sector development has itself been supported by accessible credit schemes and dedicated training. The broad spread of non-agricultural technologies, in particular ICT networks and farmer-oriented solutions, has helped these developments considerably.

This agricultural transformation has contributed to a broader change among upstream components in the food chain within rural areas since the increase in productivity and incomes enables the development of new production-related industries and services. Food processing and packaging plants are increasingly located in rural areas and small urban centres nearby, offering off-farm job opportunities for the younger generation. Farming and related activities are now considered as attractive as working in cities, and often less risky, so much so that rural-urban migration flows, in particular towards megacities, are being mitigated. Having played a decisive role in this transformation (e.g. access to and management of credit schemes), the status of women in rural areas has also improved significantly. 


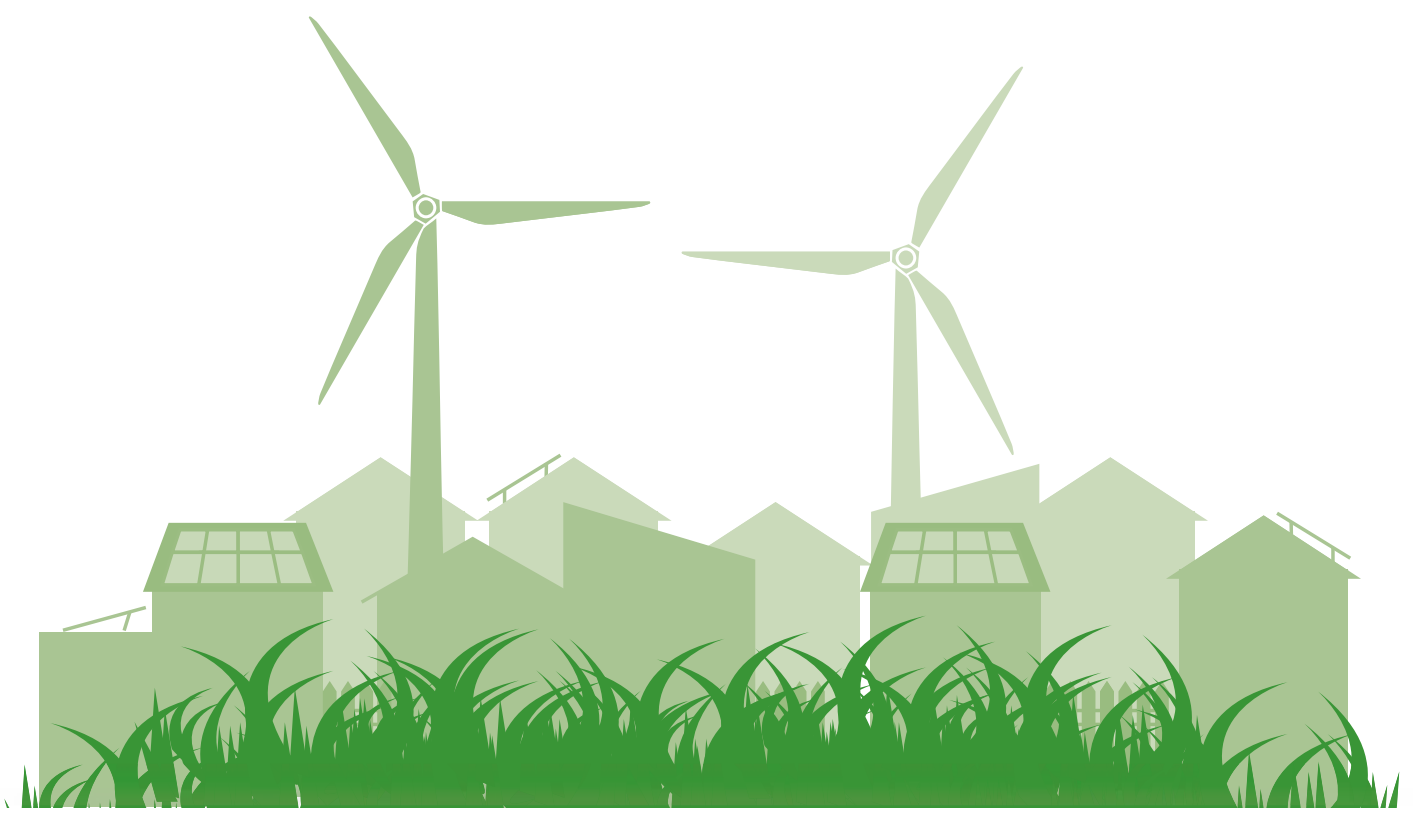

An enabling environment in rural areas

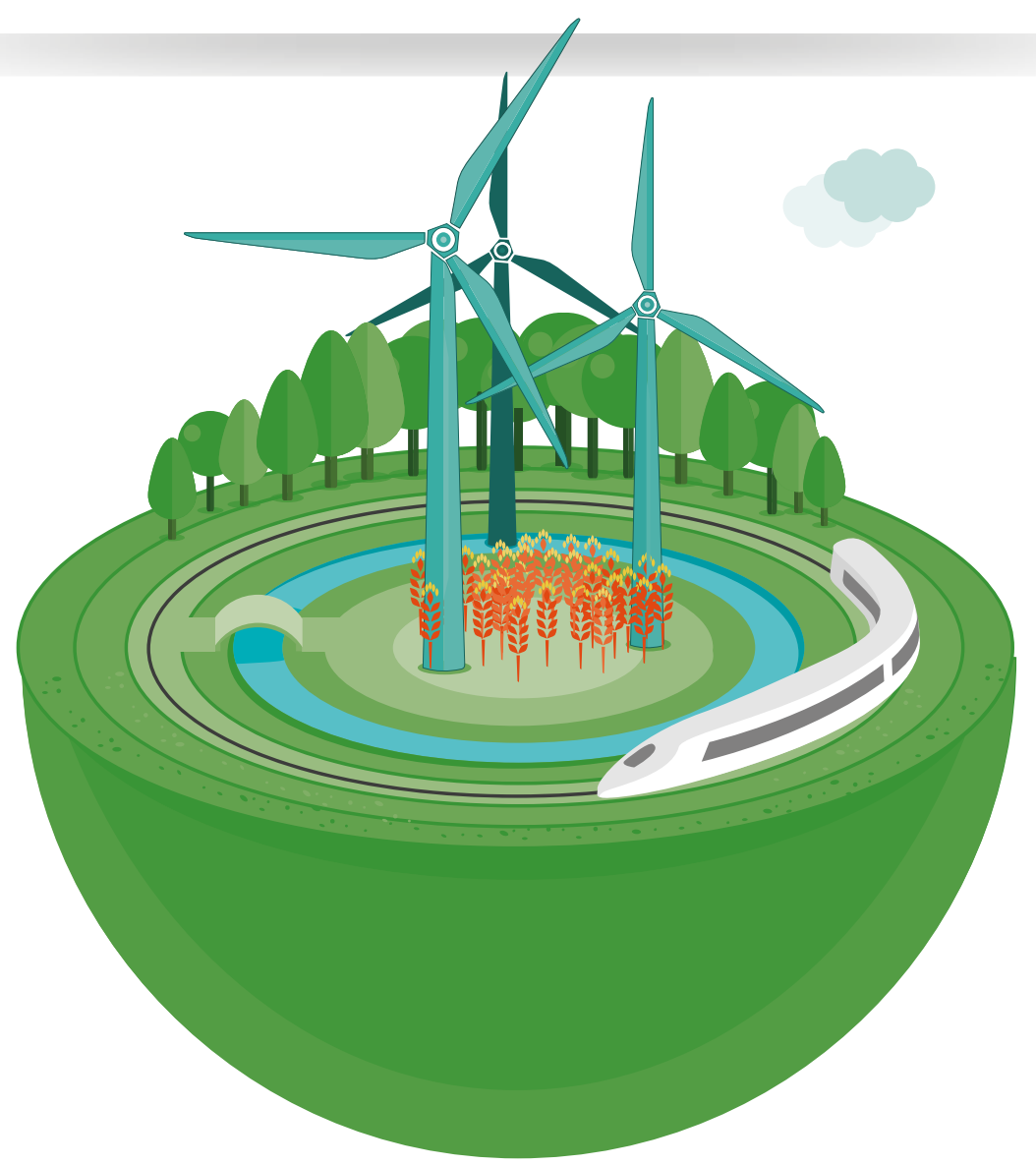




\subsection{An enabling environment in rural areas}

\subsubsection{Rural development strategies}

The true benefits of this agricultural transformation have only materialised as the result of broader rural development programmes focusing more on the enabling environment. Smallholder farmers have been removed from socio-economic isolation in terms of production inputs, knowledge, credits, technology and access to markets. This was largely initiated by strong international and national political will and significant investments from both private and public actors. Thanks to increased economic growth in most developing countries and better redistribution towards rural areas, substantial investments in costly infrastructure, including road construction and off-grid electrification, have fostered access to markets for purchasing inputs and selling agricultural products. This has triggered a virtuous circle of rural economic development by reducing transaction costs, both in terms of information (e.g. market signals, early-warning systems, etc.), physical infrastructure (e.g. transport) and organisation (e.g. bargaining power of small producers).

\subsubsection{Local resilience and social protection}

Well-targeted social safety nets are now in place to help cope with crises and shocks, as well as longerterm and more institutionalised social protection schemes to help address the underlying causes of social inequality which undermines consistent and predictable access to nutritious food. In hypersensitive climate change areas, crop insurance schemes and other risk management strategies designed to cope with yield loss caused by climate variability have been introduced to increase resilience.

\subsubsection{Stronger local governance}

The empowerment of farmers' organisations and the promotion of more decentralised governance schemes in many developing countries have enabled small agricultural producers to play a stronger role in local, national and regional food governance. The revision of land and water rights through socially equitable principles has given rural farmers a new sense of stability and ownership. Overall, there has been a decrease in corruption practised by officials, and investments resulting in greater equity. Similarly, there has been an increase in investments dedicated to strengthening the capacities of grass-roots organisations that contribute to the extension of food-related technologies and information sharing based on best practices. 


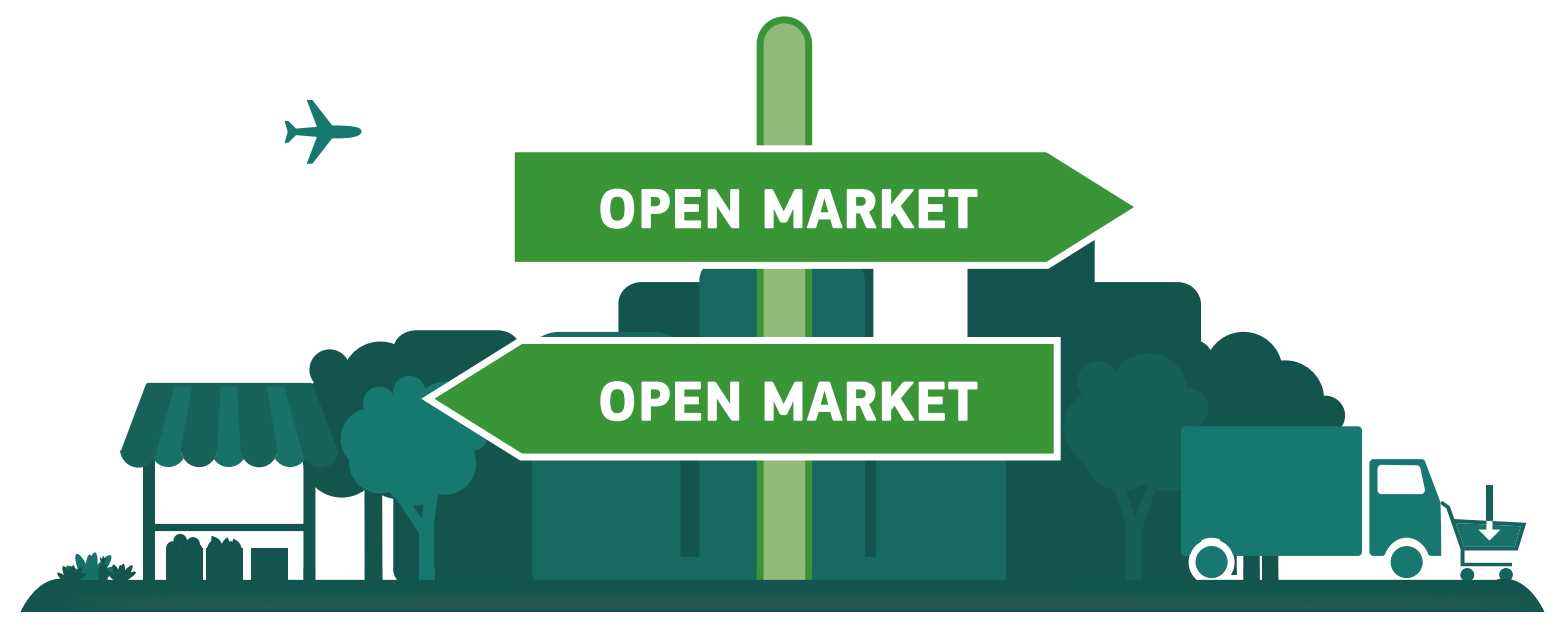

A balanced food system between local, regional and global levels

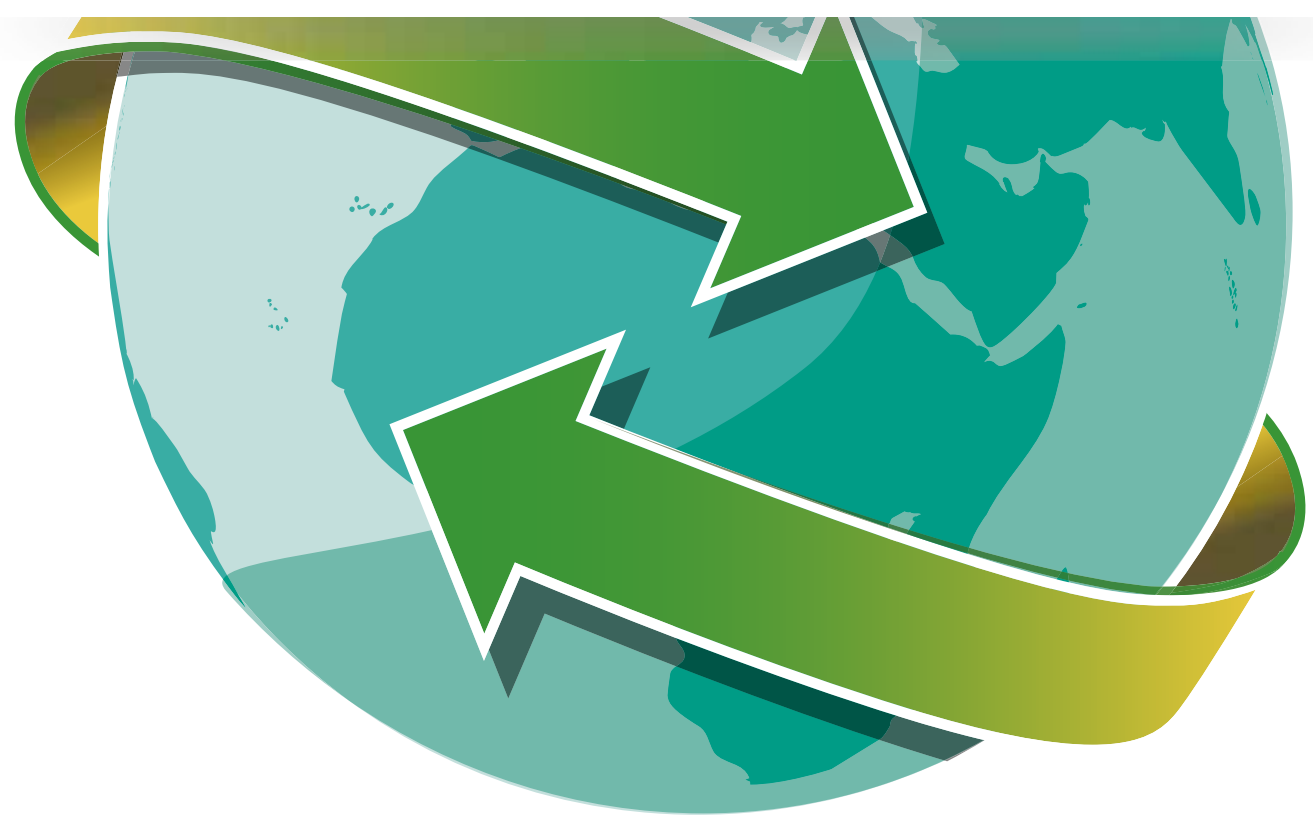




\subsection{A balanced food system between local, regional and global levels}

The 2030 food system is based on a balance between the local and global level of food production and consumption whereby what was once known as the traditional system has moved beyond self-sufficiency and subsistence, towards better productivity and integration into local, regional and global markets. The food system as a whole is characterised by a mosaic, in which various different types of food systems, at the local, national, regional and global levels, function simultaneously in pursuit of different objectives.

On the one hand, the technology-driven agro-industrial system has contributed significantly to global food availability and ensured accessibility to all sorts of food products worldwide through freer agri-trade flows, with better environmental footprints. On the other hand, more local, agro-ecological and smallholder farming-based food systems have evolved beyond the subsistence model, thanks to greater agricultural productivity and stronger integration within food markets. Those local food systems increasingly answer the needs of local, regional, sometimes global, food demand from both rural and urban areas, in return generating the income that enables smallholder farmers to access more diverse and nutritious food. Simultaneously, they have fostered the provision of ecosystem services and a more efficient allocation of natural resources, contributing to sustainable progress towards global food security. Fish production has also helped increase the sustainability of food provision worldwide since some environmental impacts of fish production are much lower than those for beef or pork. ${ }^{57}$

\subsubsection{Global governance}

In a tripartite effort, the $\mathrm{G} 20$, the African Union and the EU have taken the lead in promoting and constructing a system of global governance focusing predominantly on achieving food security by 2030 by redesigning the food system to become more sustainable and equitable. Biannual meetings held in various capitals around the world have addressed questions about the optimal use of resources in relation to the overall food system and how to create more socially responsible entrepreneurship. Global food security has become a performance indicator for large food corporations. International cooperation on food reserves management and strategies to develop targeted safety nets for the poor are permanently on the political agenda. While the system of global governance in $\mathbf{2 0 3 0}$ does not favour central planning or international management mechanisms, it has focused on finding agreements on key principles driving decision-making within national governments, regional bodies and international organisations.

\subsubsection{Regional governance}

In Africa, the Comprehensive Africa Agriculture Development Programme (CAADP) has received a significant boost through improved governance and greater investment resulting from economic growth and public-private partnerships. African leaders have vowed to work towards a hunger and malnutrition-free Africa, focusing predominantly on a shift away from dependency on imports. Through an enhanced partnership with the EU, and with food security high on the global governance agenda, knowledge transfers on land and water rights are taking centre stage. With increased cross-border cooperation to boost regional infrastructures and the extension of national social protection schemes, Africa is on its way towards creating an enabling environment in which it can reach its goals. Through a triangular energy strategy between the EU, Africa and China, investments in off-grid electrification and a focus on the electrification of vast rural areas are finally taking shape. African governments also see the need to capitalise on the opportunities provided by urbanisation. In southern Africa in particular, there is a more even distribution of industrialisation efforts, while with better infrastructure, rural-urban links are also improving.

With water and land scarcity becoming an acute problem in Asia, combined with population and income growth, the region has invested in diversifying people's diets and making the food system more intensive and more sustainable. In Asian countries, there is particular focus on developing rural areas and preventing migration flows into the urban centres, through the integration of traditional agricultural methods alongside hightech industrial production technologies. Investments in water-saving and storage infrastructure have been significantly enhanced, along with optimising the food basket by focusing on the diversity of proteins available in the Asian diet.

Governments have taken action to increase the role, power and ability of farming organisations to participate in the decision-making process, including better access to technology (especially ICTs) and credit. From both the supply and demand sides, diversified protein diets have been adopted. Fish and fish-based products 
are increasingly becoming essential dietary components and seem to be counteracting the environmental concerns associated with meat-based diets.

By 2030, Latin America and the Caribbean regions which had already seen a $30 \%$ decline in undernourished people from the early 1990s to the early 2010s, coinciding with Brazil's strong economic development - have evolved towards a model of co-existence between advanced industrial farming as a "world food provider" and small farming systems that revitalise rural areas and employ workers in these communities. While Brazil and Chile have benefited from improved market access and trade liberalisation, smaller Latin American countries have focused instead on the creation of support networks between consumer and agro-ecological food companies.

\subsubsection{Trade and markets}

Positive growth in the world economy, especially in the developing world, has created a fertile environment for the greater liberalisation of agricultural products and an eventual convergence between the treatment of agricultural and non-agricultural goods in multilateral trade rules. The Doha Development Round (DDR) was successfully concluded, and the implementation of new trade rules has started to take shape. The conclusion of the talks has led to increased trust in global governance systems and institutions such as the World Trade Organization (WTO), as well as the United Nations (UN), which has been effective in creating solidarity around effective hunger eradication and food security.

Commitments made in the 2013 Bali Package eventually came to fruition, with agricultural-related subsidies from both the industrialised and developing countries cut back significantly and export tariffs reduced: bound tariffs were cut by over a half, bringing agriculture more in line with non-agricultural tariffs. Major developing countries have been granted increased flexibility with regards to protecting their own sensitive sectors, although the liberalisation of imports of special and sensitive products has slowly started to take hold. Overall, the global market has become even more integrated, and trade liberalisation in agricultural commodities is seen as a risk-management strategy through the diversification of the food supply, which is now based on a mix of food products available on a national, regional and global scale. The world is moving towards a borderless market for agricultural and food products with consumer choice determining trade flows while sourcing from low-cost suppliers. Rather than liberalisation reducing diversity, the mix of systems has actually increased it.

Because the trade system has become increasingly globalised, food and safety standards no longer act as a barrier to trade. As capacity-building in the area of monitoring, risk assessment and regulation throughout the food chain has been significantly stepped up in developing countries, they have also become more active members of standard-setting bodies.

\subsubsection{Transparency, regulation and ethics}

Alongside the conclusions from the DDR, increased global concern over environmental issues has led to significant progress at the WTO-level on 'environmental goods and services'. Life-cycle analysis of products has been stepped up, particularly in European legislation. While Europe now redistributes subsidies according to an entirely different breakdown, it is using this leverage at the international level to lobby other WTO members to accept the setting up of a mechanism to evaluate the carbon footprint of goods. Eventually, goods are being classified in such a way that enables environmental regulations to coexist better with trade rules.

At the same time, however, significant parts of world trade in agriculture and food products are now dominated by a very small number of transnational firms. While this has increased efficiency, diversity, convenience and consumer choice, growing awareness at the global level is leading to a demand for greater transparency on the performance of food corporations and their impact on the market. While the WTO had previously excluded competition policy as part of multilateral trade discussions, renewed confidence in the benefits of multilateralism, coupled with growing concern over corporations' power, has eventually led to competition policy being put back on the agenda. As with progress on incorporating the carbon footprint into the classification of goods, there is now serious discussion on including compatible food-security actions as drivers for corporate practice. 


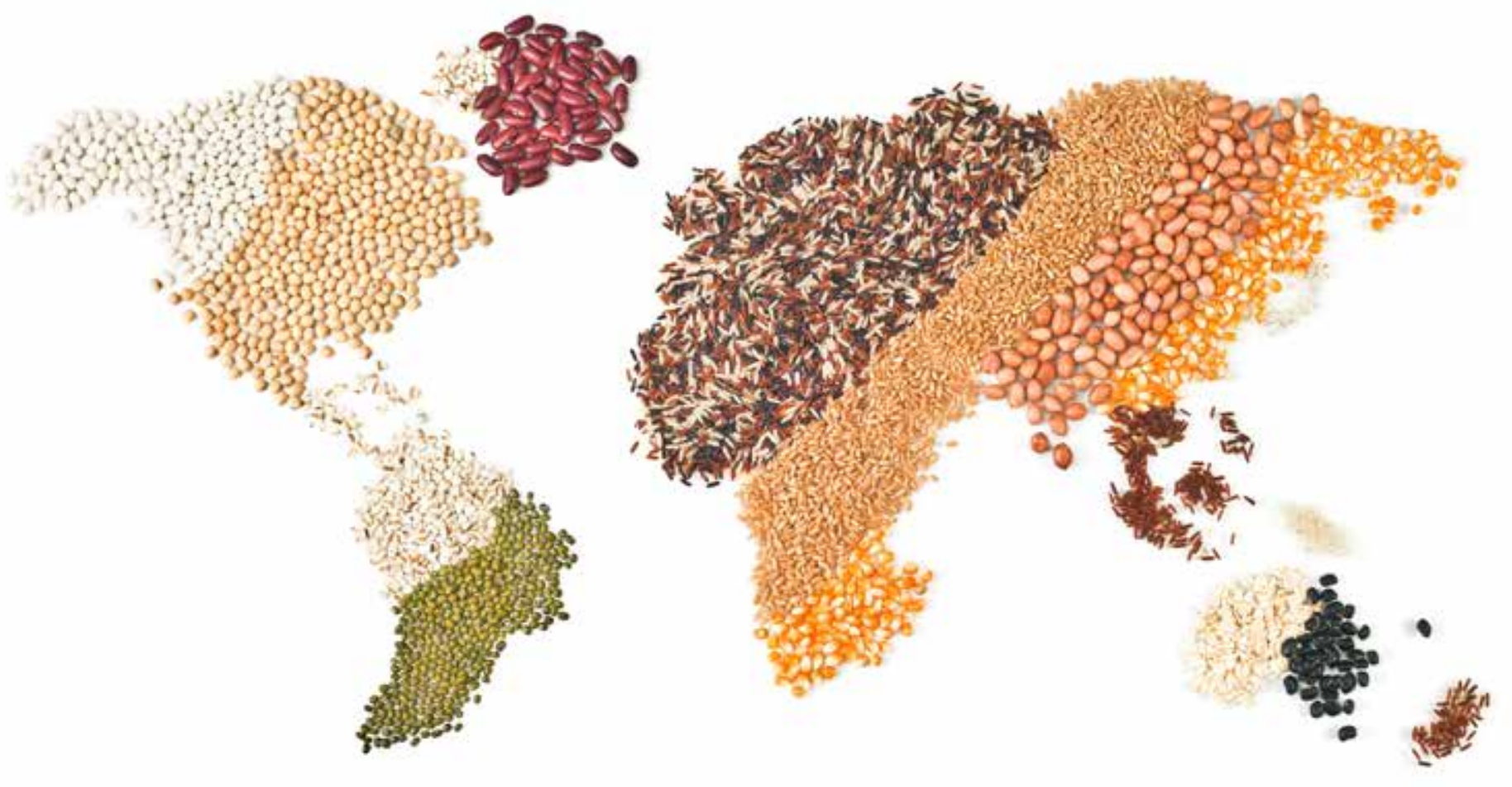




\section{0

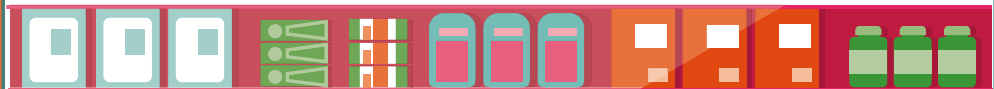

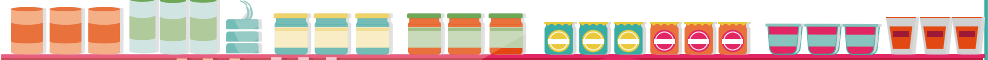

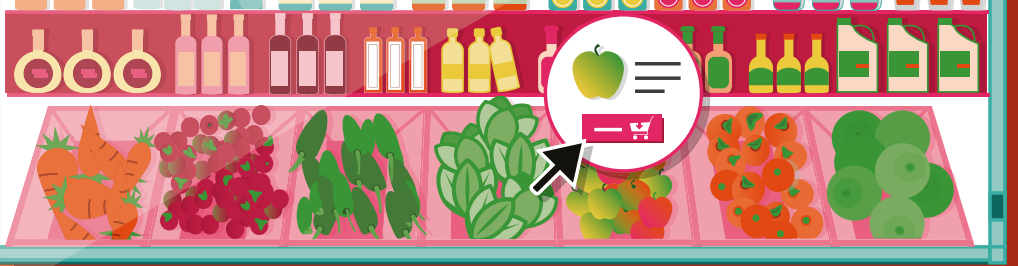

A demand-driven food system

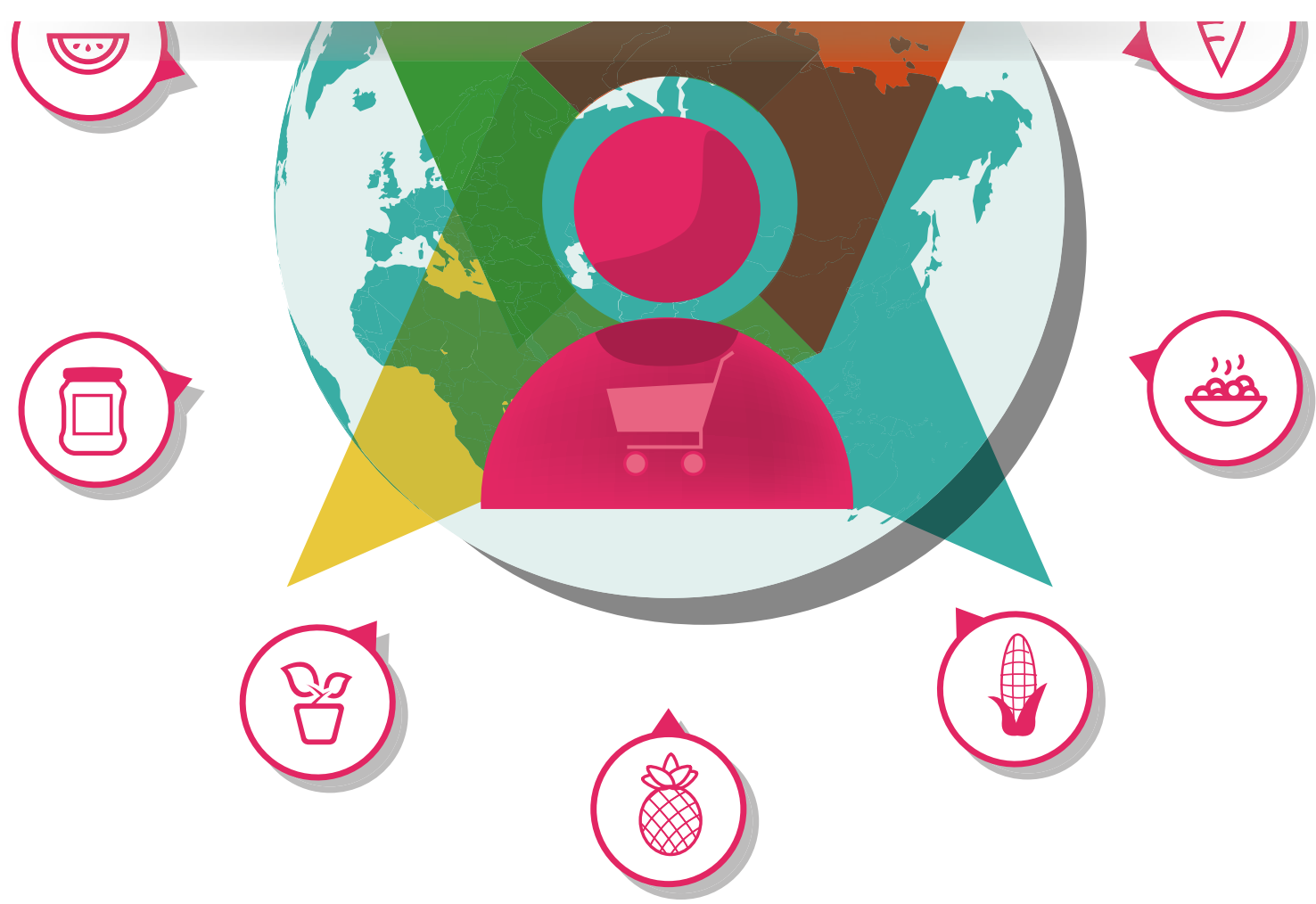




\subsection{A demand-driven food system}

The majority of 2030 food consumers will be located in Asia, where their demand is shaping global food trade. The consumer represents a formidable market force that is now adequately empowered in terms of food choice, and much better informed regarding the impact of his/her choices. This, in turn, is leading progressively to a more sustainable, diversified and healthy consumption pattern. However, consumer empowerment is not only linked to more and better choices, but it also has an influence on the market and ultimately on production systems. Continuing urbanisation further reinforces this process. Food supply is being increasingly influenced and shaped by consumer demand, and the balance of power has shifted towards the demand side of the food chain.

Higher incomes and improved well-being among the rural poor have helped to improve diets. Education and targeted nutrition programmes have been pivotal in significantly reducing the number of children suffering from stunted growth. Bio-fortified crops (with enhanced nutritional value) have become more common and useful in improving the uptake of important minerals and vitamins. In developing rural areas with rain-fed agriculture, the extra cash from staple crops is being used to purchase nutritious vegetables.

Economic growth, urbanisation, trade liberalisation and the expansion of transnational food corporations have also led to an increased intake of calories, initially from cheap foodstuffs of vegetable origin, and subsequently from vegetable oils, dairy products, animal proteins (meat) and sugar. The expansion of supermarkets and retailers enables people to access diverse and safe food, as well as cheap and less healthy food. Seafood consumption has increased, but despite its dietary benefits, there are environmental concerns about the over-exploitation of stocks.

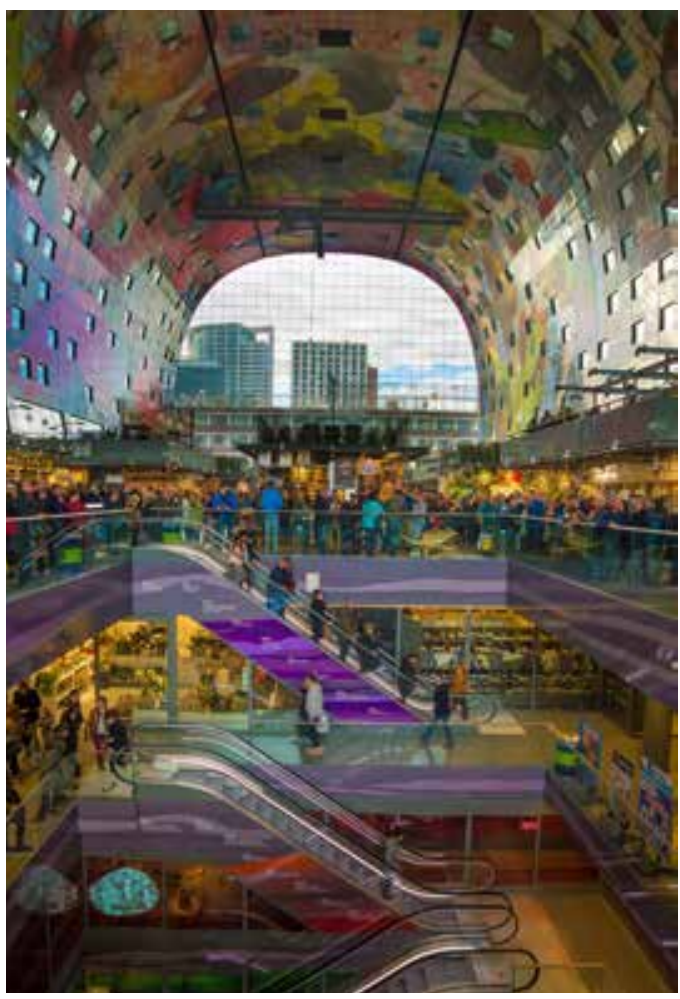




\section{Policy positioning on global food security}

Vision 2030 foresees a significant and sustainable enhancement of global food security, although scattered pockets of food insecurity still exist worldwide. The EU could have an important role to play in working towards this vision by designing, supporting and implementing policy initiatives today that could contribute towards achieving the four features of Vision 2030. To reiterate, these are:

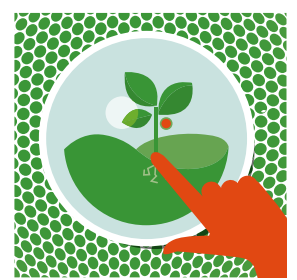

$\rightarrow$ Achieving sustainable intensification of smallholder agriculture through technology transfer and adaptation, an overall transformation of agricultural business models, and increased public-private coordination, especially in critical regions in Africa and South Asia (section 3.1.);
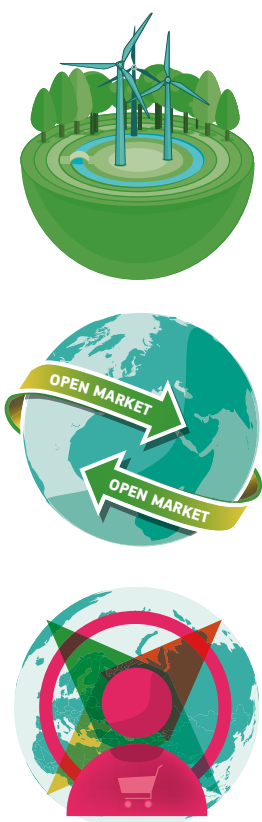

$\rightarrow \quad$ Creating a pro-poor enabling environment in these African and South Asian regions through rural infrastructure development, resilience-building and social protection, and strengthened local governance (section 3.2);

$\rightarrow$ Promoting and building on a more balanced mix between local and global food systems to ensure that the four dimensions of food security can be improved simultaneously, which implies stronger global governance and freer and more transparent markets and trade (section 3.3);

$\rightarrow$ Promoting and building on demand-driven food systems by empowering consumers, a stronger focus on nutrition, and increased awareness of sustainability issues worldwide (section 3.4).

Currently, EU policies are aligned with meeting the first two objectives: agricultural transformation and the creation of an enabling environment. For the other two - a balanced and demand-driven food system - the policy framework on food security will need to adopt a more comprehensive and integrated food-systems approach if it is to tackle the challenges ahead and the opportunities that arise.

\subsection{Current policy priorities for food security}

Food security has become one of the international development agenda's top priorities, enjoying a particular boost after the 1996 World Food Summit, the setting of the Millennium Development Goals (MDGs) in 2000, and even more so after the 2007-2008 world food-price crisis, signalling the need for a stronger food security agenda. The focus on agriculture has been prominent within this agenda. In its World Development Report 2008, the World Bank emphasised that agriculture offered the best return on investment to eradicate poverty, as well as an opportunity to create synergies for the sustainable management of natural resources. Consensus on the need to boost funding in agriculture (through aid, public spending or private investment) has grown over the years, as has the trend towards increased national budget allocations to agricultural development. In Africa, raising agricultural productivity by at least $6 \%$ from 2003 to 2015 was defined as the main objective of the Comprehensive Africa Agriculture Development Programme (CAADP).

At the global level, the G8 L'Aquila Food Security Initiative, launched in 2009 in response to the 2007-08 world food-price crisis, focused largely on sustainable agricultural development. In 2011, the G20 endorsed an Action Plan on Food Price Volatility and Agriculture to deal with volatility in food prices by targeting increased agricultural production and productivity in developing countries, better market information and transparency, stronger international policy coordination, enhanced risk management and financial regulation. In 2012, the G8 world leaders launched the New Alliance for Food Security and Nutrition (NAFSN), intended to boost agricultural productivity, domestic and international private-sector investments, support innovation and technology in Africa, and improve risk management. Meanwhile, the Scaling Up Nutrition (SUN) initiative has become a leading platform where decision-makers, businesses, researchers, civil society and other stakeholders from those countries affected by malnutrition coordinate to improve nutrition in the fight against hunger. 


\subsubsection{European food and nutrition security policies}

For the EU, food security has been a priority on the development agenda since the launch of the MDGs, and even more so since the food crisis. This crisis led to the creation of an EU Food Facility, which provided EUR 1 billion over three years (2009-2011) to improve agricultural productivity and food supply in the 49 most affected countries.

In 2010, the EU and its Member States adopted an EUwide policy framework for food security..$^{58}$ Since then, further EU development policy commitments have been undertaken to reinforce the priorities established in 2010: the nutrition policy framework, ${ }^{59}$ together with the EU approach to resilience, ${ }^{60}$ further bolstered food security pillars three and four (regarding the nutritional adequacy of food intake and enhancing crisis prevention and management, respectively). In 2013, an Implementation Plan for Food and Nutrition Security was produced and divided into six policy priorities:

- Improving smallholder resilience and rural livelihoods (in particular through sustainable agricultural intensification and diversification);

\section{- Supporting effective governance;}

- Supporting regional agriculture and food and nutrition security policies;

- Strengthening social protection mechanisms for food and nutrition security, particularly vulnerable population groups;

- Enhancing nutrition in particular for mothers, infants and children; and

- Enhancing coordination between development and humanitarian actors to build resilience and promote sustainable food and nutrition security.

From 2014 onwards, the European Commission will jointly produce with the Member States consolidated EU-wide biennial progress reports. The first of these will review the performance of the EU and its Member States in executing the Implementation Plan.

Regarding its main areas of intervention, the EU considers that "sustainable small-scale food production should be the focus of [its] assistance to increase availability of food in developing countries", and that "intensification approaches" should be prioritised. Strengthening social protection mechanisms, scaling up nutrition actions at country level, and building resilience in the most food insecure and vulnerable countries are also strategic priorities.

Furthermore, the EU Food Security Policy Framework recognises as a fundamental principle that food security strategies need to be country-owned and country-specific, and that each country should seek "an appropriate balance between support to national production and covering food needs through trade". This emphasises the need for coherence in the international food-related governance system, as well as between donor interventions (i.e. aid harmonisation, alignment, ownership and effectiveness) and among different food security-related EU policies (i.e. focus on policy coherence for development). Coordination with private investment and/or humanitarian action is also increasingly sought.

\subsubsection{European non-development policies impacting global food security}

The current EU Food and Nutrition Security Policy focuses strongly on development aid interventions, while recognising that non-development policies can impact global food security. That is why the EU, through the Policy Coherence for Development (PCD) approach, seeks to minimise inconsistencies and build synergies between policies other than development cooperation that may have an impact on developing countries. The PCD approach is particularly important regarding food security since the EU is one of the biggest economies in the world, the largest agro-food importer, the second largest exporter, and consequently is a crucial stakeholder in all non-development policies, including agricultural policy, trade, research and development, innovation, biodiversity, land use and the impact of bioenergy production, and fisheries policy. The potentially negative impacts of these policies on global food security have been taken into account more and more over the last 20 years, in particular through the reforms of the Common Agricultural Policy (e.g. the do no harm principle), the Common Commercial Policy (e.g. the Generalised Scheme of Preferences and the Preferential Trade Agreements) and the Common Fisheries Policy.

Yet, in order to achieve all four features of Vision 2030, coherence amongst these policies will have to materialise substantially into more concrete actions. While the EU's development and agricultural policies are aligned to meet the first two features of Vision 2030 (agricultural development and an enabling environment), real policy coherence could provide a further push towards meeting the challenges associated with achieving a balanced, yet demand-driven and sustainable food system.

\subsection{Current EU policy positioning on Vision 2030: missing the bigger picture?}

Overall, current EU food security policies and initiatives are largely in line with the first two key features of our shared vision for food security in 2030. In a nutshell, these interventions put smallholder farmers in the most food-insecure regions at the centre of the strategies and rely on the transformation of their own activities into a competitive and sustainable agri-business which is expected to enable three objectives to be achieved: 1) ensuring food security; 2 ) escaping the poverty trap; and 3) fostering the sustainable use of natural resources. Within this approach, global food

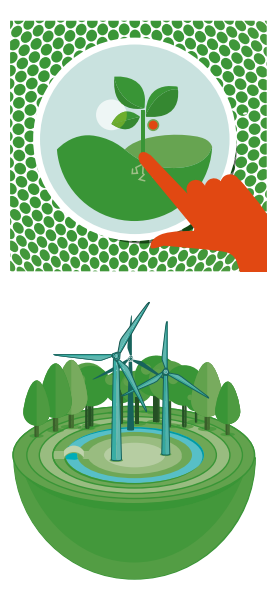




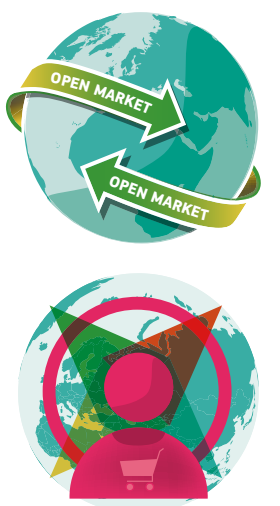

markets provide an arena for new fruitful opportunities for smallholder farming, as long as infrastructure, risk-management mechanisms and information systems are put in place. A special focus on nutrition is also a major component of these interventions (see the SUN initiative), and global coordination between public and private stakeholders (see the NAFSN initiative).

Vision 2030 also calls for concrete actions to promote and build a more balanced mix between local and global food systems and to acknowledge (and foster) more demand-driven food systems by empowering consumers who would like better control over the nutritional aspects of what they eat and want to contribute to sustainability issues worldwide. On the latter two aspects of Vision 2030, however, EU food security policies neither seem to fully consider nor address the challenges and opportunities that are likely to arise from the changing demographic and socio-economic trends that could significantly transform the future food system. Instead, current food security policies focus mainly on targeting those pockets of food insecurity, where hunger and malnourishment persist now and may or may not do so in the future. While such policies are certainly worthwhile and commendable, they seem to miss the bigger picture - namely that food security will increasingly be considered as a means of securing food supply in answer to new and emerging trends in demand. This requires that the role of trade and markets in securing this supply, and the extent of these changing trends in demand should increasingly be considered and integrated into EU food security policy (see Figure 2).

\subsubsection{Uncertainty in trade and markets}

Domestic and international trade plays a fundamental role in global food security. It also allows countries with a comparative advantage in the production of agricultural commodities to specialise in these activities and to sell and export food and agricultural commodities and purchase other products with the resulting revenues. The same applies within the agricultural sector itself since most countries export

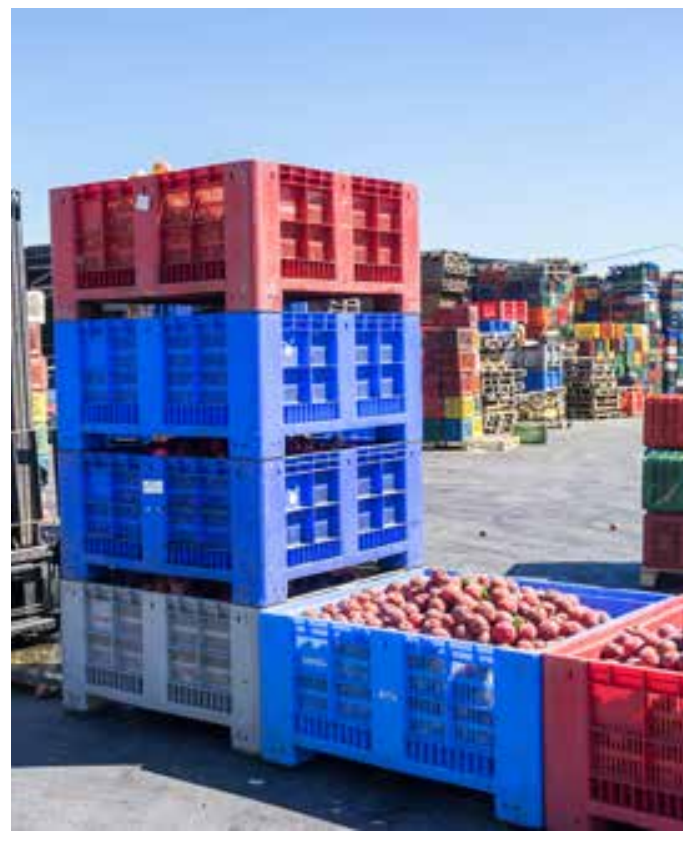

agri-food commodities and import other products. Trade in food and agricultural products has evolved strongly in recent decades: traded volumes and values of agricultural products have increased; trade flows in terms of origins and destinations have changed; and international trade agreements have enabled freer trade between nations.

In Vision 2030, the development of a balanced food system foresees steady economic growth, further liberalisation of markets and trade, increased transparency and regulation of the food system, and improved global governance on food. In reality, however, such a transformation is mired in uncertainty. While the last 30 years have been marked by increased liberalisation and globalisation, a number of uncertainties could significantly hinder or even reverse this trend, as illustrated by the current deadlock in the WTO Doha Round and the ultra-sensitivity of agricultural topics in ongoing regional trade agreements (e.g. trans-Atlantic and trans-Pacific). Therefore, the direction in which the evolution of domestic, regional or multilateral institutions will go is questionable. If we continue down
Fig. 2: From food insecurity to a food-systems approach

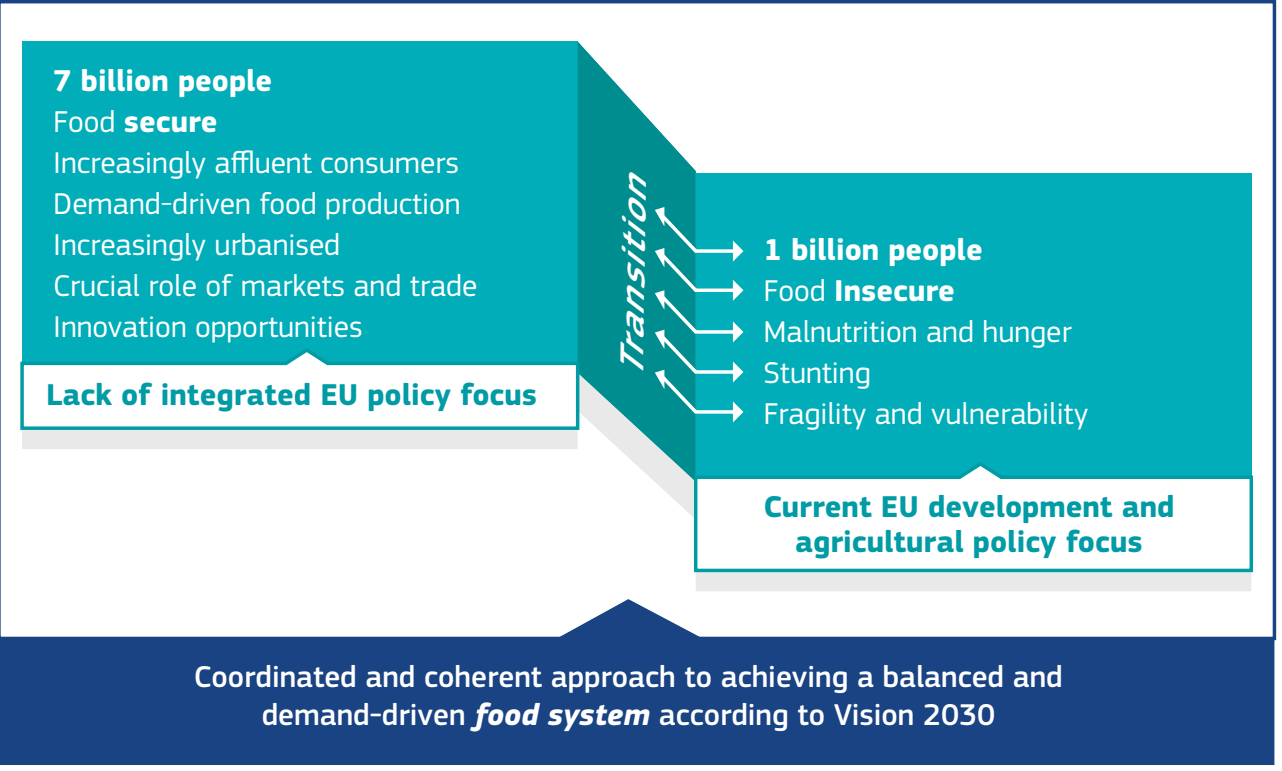




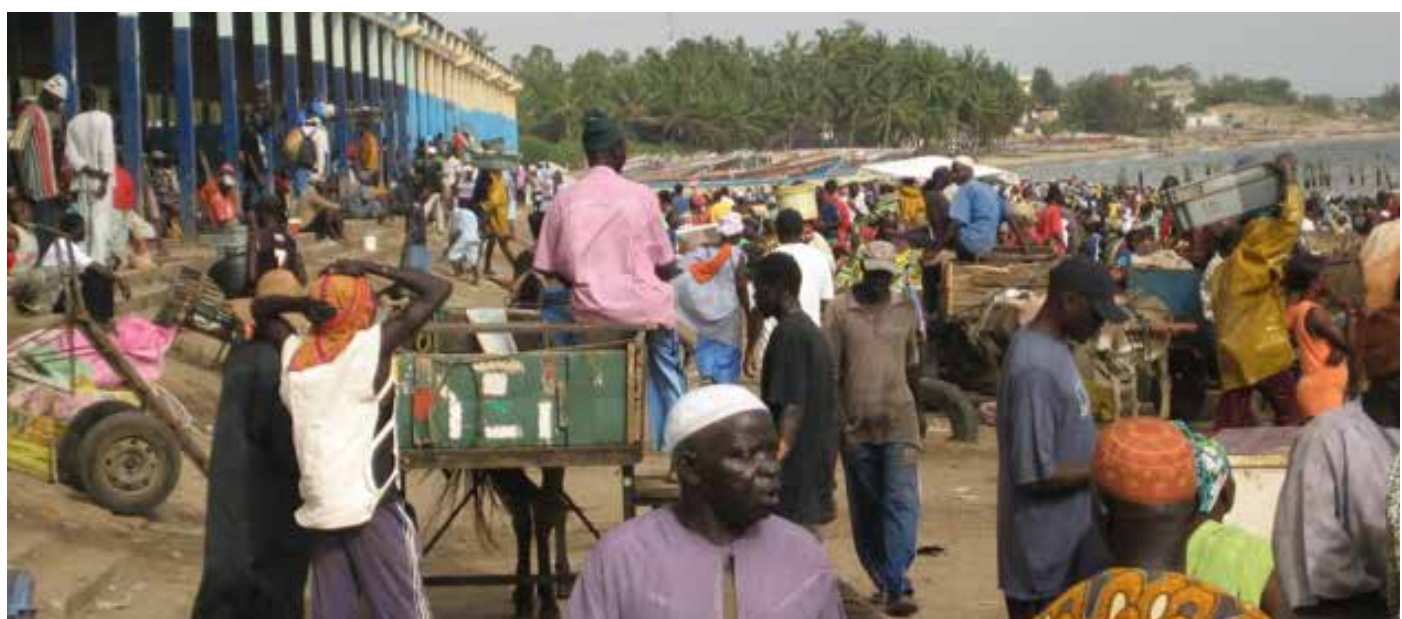

the current path, the focus could be on consolidating and furthering progress on what has already been done, to the point where agriculture and food products are completely liberalised by the removal of tariff and non-tariff barriers, as foreseen in Vision 2030. On the other hand, the difficulties that have already been encountered in negotiating agricultural trade, especially at the international level, make it uncertain as to how much new ground trade talks can really break in the next 15 years. Any further opening up of agricultural trade may continue to struggle with problems of governance as economic power continues to shift from the West to the East. Tensions may grow between development goals and reducing transaction costs, while only partial success will be achieved in simplifying the trade rules. At the same time, an opposite trend is emerging which points towards a resurgence of national concerns over food security, especially in emerging and developing economies, as well as a preference for shortening supply chains, bringing production closer to the consumer, and reducing the overall environmental impact of the food system.

The impact of food quality and safety standards on trade and global supply chains is also a matter of uncertainty. In recent decades, product quality and food safety requirements have increased rapidly, and standards on the ethical and environmental concerns of food production have become more important. The food trade, especially with the EU, US and other high-income regions, now has to satisfy a series of stringent standards imposed by public bodies and private companies. This poses challenges for the participation of developing countries in high-standard agricultural trade which, in turn, may have negative effects on their food security. On the other hand, perhaps it is the case that high-standard global supply chains can bring important benefits for poor rural households. In this case, the rapid rise in food standards does not necessarily lead to new barriers to trade and to a more inequitable distribution of the profits, but can also enhance developing countries' participation in high-value international food markets and contribute to development in these countries.

A further uncertainty comes from climate change, which could reduce production capacities in some regions while increasing them in others. International trade can play a valuable role in offsetting the negative effects of climate change on productivity by allowing those regions enjoying a positive effect on yields to supply those where yields are being negatively affected.

The future of the global trading system is crucial in determining the successes and failures in achieving global food security and, indeed, Vision 2030. Yet, what would happen if there was a reversal in the trend towards trade liberalisation and the globalisation of agriculture and food? What possible trade-offs exist when envisioning the future of trade and its implications on food security? In policy terms, what role can the EU play in shaping and effectively participating in this future system, and how will it address the trade-offs that are certain to occur? Such issues have yet to be thoroughly addressed at the level of EU policy on food security - indeed, much of the discourse seems to be based on the assumption that the trade system will invariably continue to become more liberalised and integrated. However, any considerations of Europe's role in the quest for global food security in the future will certainly need to take greater account of the uncertainty that exists around the evolution of trade and markets.

What would happen if... international trade in agriculture broke down?

"After the 2008 food and financial crises, global economic growth continued to slow while price volatility increased. Political and social tensions became an all-too-common feature of the next two decades. A number of food crises between 2016 and 2020 were yet another reminder that the global food system was unable to feed the most vulnerable populations in many countries, and that smallholders in developing countries would continue to struggle to take their place in the global market. Geopolitical instability across the globe, and particularly in oil-producing countries, led to continuing spikes in oil prices, while alternative sources of energy proved unable to penetrate the African market in particular. Even for competitive farmers in developing countries, increasing input costs in agriculture began to outweigh the benefits of higher selling prices. A veritable backlash against the international trading system in agricultural commodities took hold across most of the world..."

To find out what happens next, and the implications for food security, go to page 34 


\subsubsection{Changing demand and urbanisation}

As regards the development of a demand-driven food system in Vision 2030, we also see uncertainty arising from the changing socio-economic and demographic drivers of the food system. A rapidly growing middle class, mostly in Asia and Africa, is likely to put significant pressure on the food system with an increasing demand for meat and dairy products. Over the past 50 years, these dietary changes, which are largely associated with increased consumer wealth in general, and most recently in countries such as China and India, have led to a $~ 1.5$-fold increase in the global numbers of cattle, sheep and goats, with equivalent increases of $\sim 2.5$-fold and $~ 4.5$-fold for pigs and chickens, respectively. ${ }^{61}$ The expansion of the middle class is closely linked to the continuing urbanisation of the world population, whereby $60 \%$ of whom will be living in cities by $2030 .{ }^{62}$ Urbanisation, along with a growing income, are bringing substantial changes in demand for agricultural products and redefining how farmers, companies, corporations, and local and national economies cope with growing demand. This phenomenon can pose major challenges for urban and rural food security. ${ }^{63}$

Among the drivers generally mentioned in forward-looking studies and predictive models related to global food security, urbanisation is seen as one of the most certain ongoing trends. Baseline scenarios usually integrate an increase in the world's urban population from 3 billion to 7 billion between 2010 and 2050, with most of this growth occurring in developing countries. It is generally acknowledged that by 2050, $70 \%$ of the world's urban population will live in Asia and Africa, which will be urbanised at least at $65 \%$ and $55 \%$, respectively. Thus, the fact that developing countries increasingly face an urban future has been widely accepted.

Urbanisation can be the source of either additional constraints or new opportunities for enhancing food security

\section{What would happen if... the world was hyper-urbanised?}

"In 2030, the world's economy is almost fully globalised. An increasing number of bilateral, regional and supraregional trade agreements and improvements in WTO negotiations have led progressively to a strong level of trade liberalisation everywhere. Trade barriers in particular have been removed on agricultural and food products, which can now move freely across and within continents. These trade flows, increasingly determined by consumer choice, have become a cornerstone in feeding a large part of a global population, which has reached 8.5 billion people, as anticipated in the 2010 s. However, global food insecurity has remained very important while patterns of food insecurity have become more and more scattered. If the gap between developed and developing countries has been reduced in terms of food and nutrition security, massive and growing inequalities in food access have developed at a sub-level, in particular between cities, across cities, and within urban and peri-urban neighbourhoods. One of the main causes of this persistent inability of food systems to ensure food security lies mainly in the global inability to cope with urbanisation in Africa and Asia, which is higher than was anticipated in the 2010s..."

To find out what happens next, and the implications for food security, go to page 36

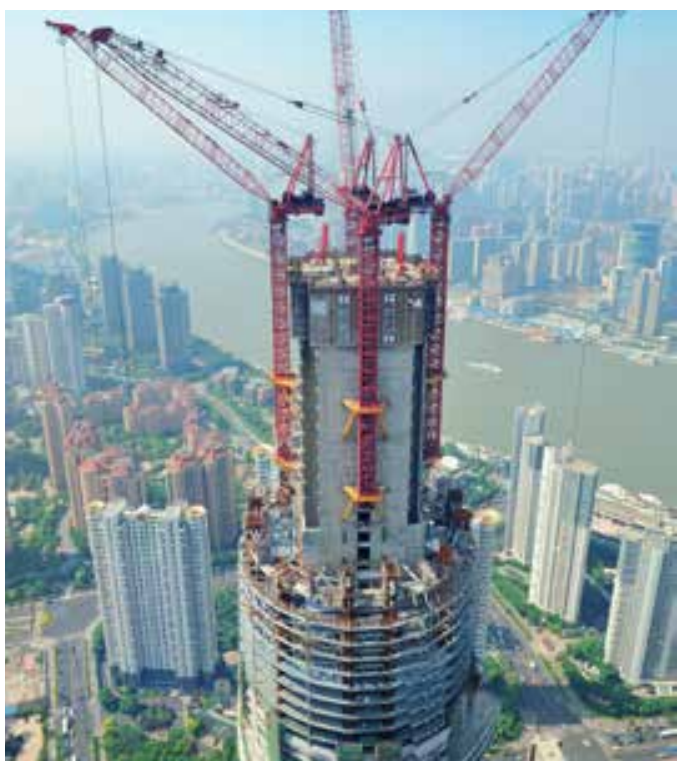

both in urban and rural areas, yet it has hardly been seen as a key driver for food security and, in fact, is a largely underestimated phenomenon as regards its potential impact. Although food insecurity is likely to become an urban challenge for decades to come, it remains largely disregarded in the international food security agenda. Growing cities in developing countries face the emerging and less-visible crisis of food insecurity, characterised by growing poverty, hunger and malnutrition, poor dietary diversity, strong inequalities in access, child wasting and stunting, increased vulnerability to infectious and chronic disease, and a growing obesity epidemic. All of these food security challenges - which follow specific patterns in the context of urbanisation - are growing in magnitude but currently receive little attention from the policy and research communities concerned with global food security.

Overall, despite the holistic FAO definition and the increasing attention being given to the access and nutrition dimensions of food security, by and large the current international food security agenda is rural, focusing mainly on production, and smallholder-oriented. The underlying rationale for this focus is that more than $65 \%$ of the poor are rural, agriculture has been underfunded for decades in developing countries, agriculture offers the best return for investment, and there is a structural 'urban bias' in favour of cities. Although the current focus makes perfect sense - which is why there is a general consensus on it - it fails to acknowledge three things: first, that there is already a high level of urban food insecurity; second, that the ratio between rural and urban poor seems likely to reverse soon, which is a situation that should not be overlooked, at least in the research agenda; and third, that there are usually 'two cities within a city' and many urban dwellers do not benefit from any such urban bias in terms of food security.

Furthermore, it is important to keep in mind that urbanisation also presents opportunities for alleviating poverty through economic and political development and growth. Urbanisation patterns are closely linked to the expansion of rural activities. Indeed, managed development in urban areas is intrinsically linked to growth in rural areas, and 
therefore can become mutually reinforcing. Furthermore, urban concentrations and emerging secondary towns (with fewer than 500000 people) play an important role since they are grounds for the expansion of new businesses (new opportunities) without generating a complete disconnection with the rural environment. In contrast to migration to megacities, which may lead to irreversible urban migration, lock-in and the "urbanisation of poverty" ${ }^{\prime \prime 4}$ secondary towns or other forms of urban concentrations may absorb unskilled and semi-skilled workers in a variety of activities. Urbanisation could significantly challenge the food system, although efficiency, innovation and sound planning across the entire food chain (e.g. assembly, handling, processing, packaging, transport, storage, wholesale and retail), can prove to be sources of significant opportunities, new jobs and growth.

From the EU policy perspective, urbanisation and, indeed, changing demand dynamics, have not been thoroughly considered as potential game changers for the future of global food security, as stipulated in Vision 2030.

Although urban food insecurity is acknowledged in the EU Food Security Policy Framework, no reference is made to the urban context in the current EU Food Security Implementation Plan for the period 2014-2020, nor is EU funding for research oriented towards urban food security patterns. Indeed, there are many knowledge gaps and a wide-ranging programme of research and policy dialogue is urgently needed to uncover the dimensions and complexities of the phenomenon.

\subsection{Achieving Vision 2030}

While uncertainties regarding the future trade system seem likely to persist and demographic and socio-economic transformations are likely to occur regardless of EU policy intervention, the role the EU can play in the future food system can be substantially enhanced through policy interventions made today, with the view of securing a more crucial and determining role in the future. However, the lack of EU policy intervention or, indeed, the failure to consider uncertainty in trade and markets and/or to underestimate changing demand and demographic trends, could lead to significant challenges in the future, or even a missed opportunity for Europe. Indeed, as regards the major transformation foreseen in Vision 2030, namely the development of a more balanced and demand-driven food system, it is apparent that current trends and major uncertainties could jeopardise the achievement of the latter two features in Vision 2030. This is likely to be the case if a more comprehensive and integrated approach to food security does not materialise into policy actions which capitalise on the opportunities found in such changing trends.

A comprehensive food-systems approach is necessary, which focuses on tackling pockets of food insecurity while, at the same time, is prepared for the challenges and opportunities related to feeding a more affluent, demand-driven, and increasingly urbanised majority of the population.

The food system of the future will be intimately connected to urbanisation trends and patterns. In this context, food security will increasingly be seen as "securing the supply of food that answers the emerging demand". Future urbanisation will evolve through a rurbanisation (the progressive transformation of rural into urban areas) or a metropolis model (enlarging existing cities or building new ones). The types of spatial mosaics that will emerge will generate a new city-countryside mesh of interactions. With the help of city-based capital and knowledge, the peri-urban rural producer will be pressed to engage in providing urban consumers with high-nutritional-value foods (vegetables, fruits, poultry, dairy, etc.). This type of short food chains will have a positive impact on the environment, rural development and urban health. The huge urban demand for carbohydrate-based products (grains) will continue to be satisfied mainly by the interregional or global market.

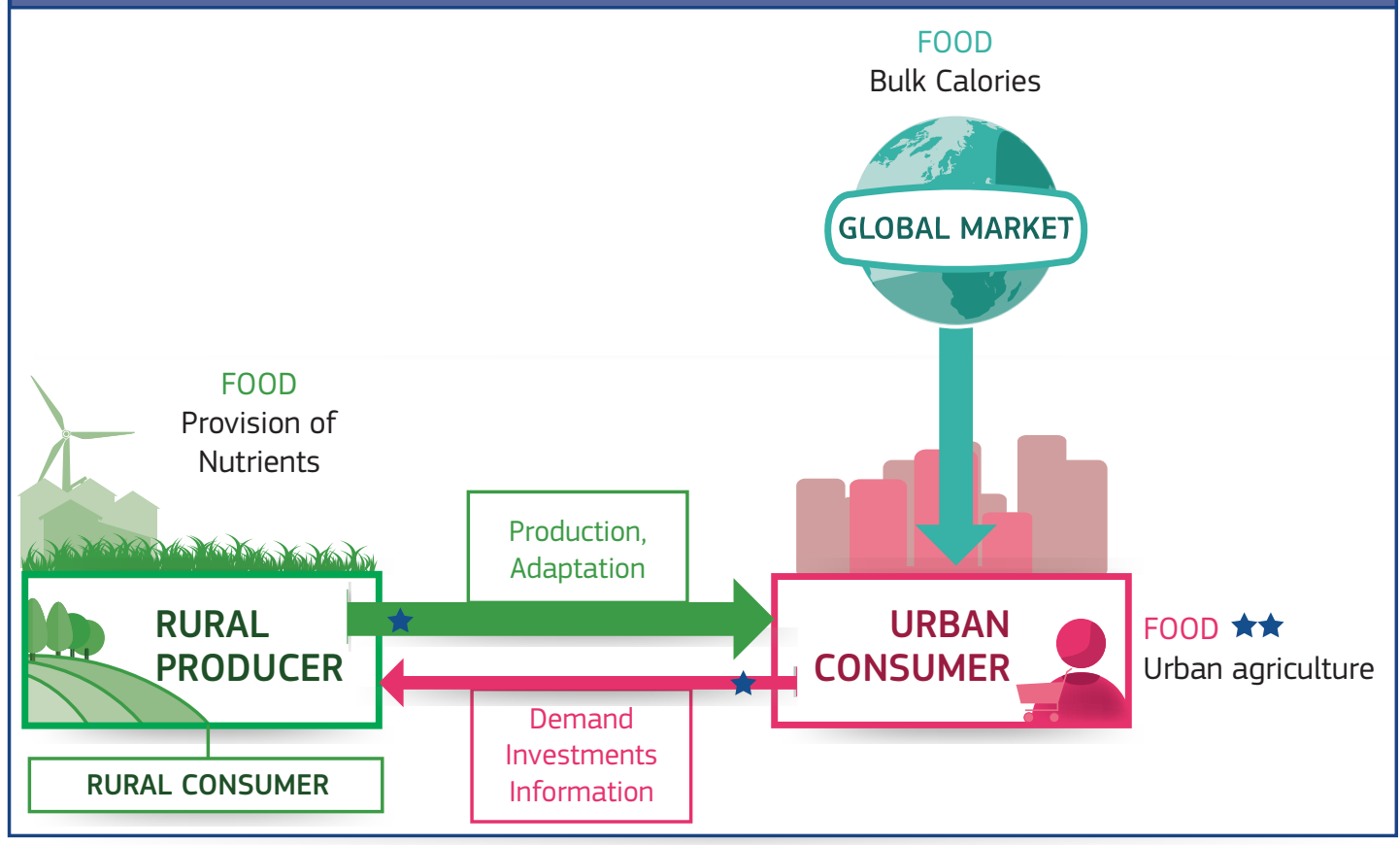

Fig. 3: The food system of the future 


\section{Key messages and policy recommendations}

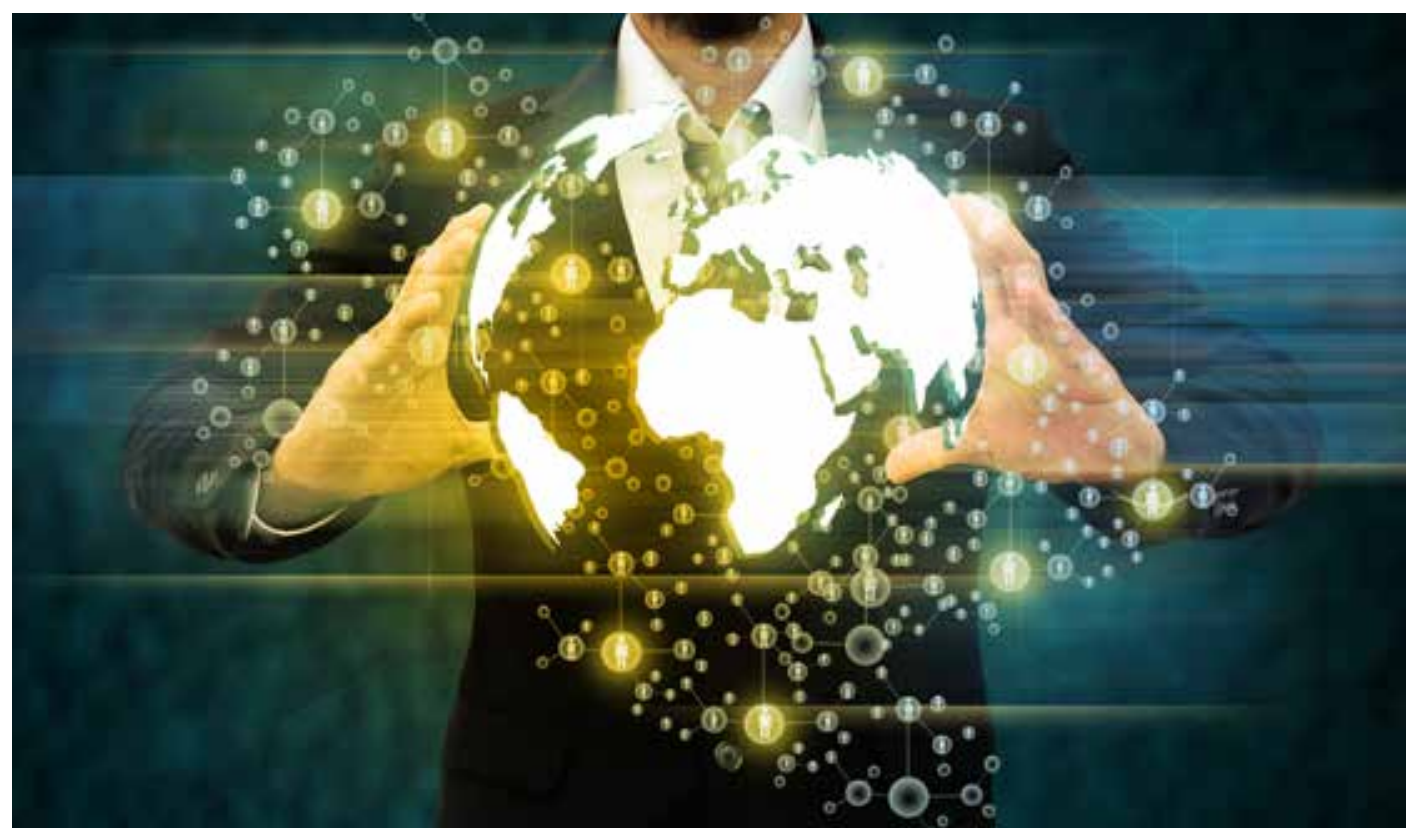

Although the world seems well aware of what needs to be done to sustainably improve food security and how policies could support this process, it seems inadequately prepared to deal with unexpected events, or underestimated trends, including the challenges that may occur and the opportunities we may create. While urbanisation and trade regimes have been touched upon in the literature and public debate as additional elements of the food security narrative, they rarely appear as main drivers or those deserving special attention, and are seldom considered as determining factors in current food security policies.

Interlinkages occur between the multiple components of the food system that can no longer be dealt with as isolated compartments, but rather must be addressed as an interconnected system. To achieve food security, a change in mindset is urgently required. While agricultural transformation and poverty alleviation should certainly remain objectives beyond the Millennium Development Goal-post, thinking about food security as such may need to be transformed into thinking about changing food systems as a whole. The dialogue on food security should continue to focus on the issue of hunger - i.e. those scattered pockets of food insecurity which persist even in our plausible yet optimistic Vision 2030. But the real challenge of feeding a world of 8.5 billion people in 2030 lies not only in continuing to focus on hunger, but also in addressing the idea of a changing food system, characterised by consumption and demand-side challenges, such as a growing and increasingly affluent population and rising urbanisation. Therefore, we suggest that Europe may want to carefully consider tackling food security challenges by continuing policies that address hunger while integrating new policies that simultaneously address food systems focusing on the needs that will arise from future global markets.

For the purposes of prioritisation, below we outline the main policy actions which will require the most urgent attention, as well as those that will need consideration in the medium term, if the EU is to contribute to achieving food security by 2030 . 
KEY MESSAGE 1

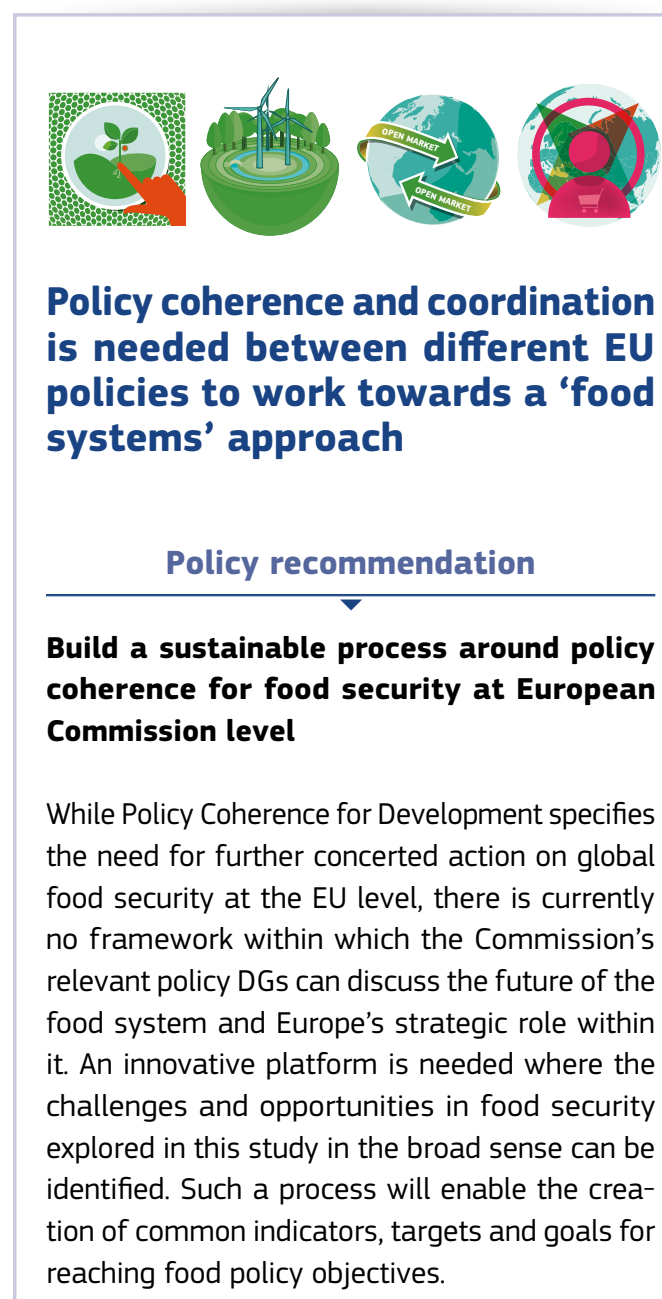

\section{Policy coherence and coordination is needed between different EU policies to work towards a 'food systems' approach}

\section{Policy recommendation}

Build a sustainable process around policy coherence for food security at European Commission level

While Policy Coherence for Development specifies the need for further concerted action on global ood security at the EU level, there is currently relevant policy DGs can discuss the future of the food system and Europe's strategic role within it. An innovative platform is needed where the challenges and opportunities in food security explored in this study in the broad sense can be tion of common indicators, targets and goals for
KEY MESSAGE 2

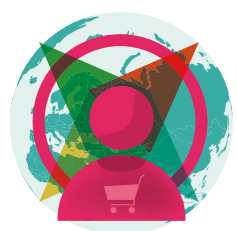

\section{Clearer recognition that "feeding the world in 2030" will essentially be "feeding the cities"}

\section{Policy recommendations}

\section{Stronger European research efforts in urban food systems and urban demand}

Research is required in order to better understand the specific drivers and patterns of food demand, supply, production and security in megacities. Urbanoriented food security indicators should be developed or current food-security indicators adapted.

\section{Stronger integration of the urban context within the European Food and Nutrition Security Policy Framework}

Global food security will primarily become a future urban challenge. However, the current international food-security agenda is rural-oriented and still focuses more on food availability than on food access and nutrition (the two key food security dimensions in urban contexts). Since adaptations of current food security policies and governance will be needed they should be anticipated and prepared now.

Stronger coordination with municipalities and local authorities worldwide on food security issues

New operational approaches should be experimented directly with municipalities to address food security in food-insecure countries. A strong focus of such joint interventions should be on strengthening rural-urban linkages, diversifying and adapting social protection schemes to local contexts, better involving the informal sector, integrating water and food security management, building partnerships with supermarkets, etc. 
KEY MESSAGE 3

Increased recognition of the crucial
role of demand-side dynamics in
shaping future food systems

Promote and develop the coherence of existing dialogue on and instruments of global governance, trade and food security

While the prevalence of the multilateral trading system through WTO negotiations should be reaffirmed in order to reach a balanced and inclusive global trading agreement, there is also a need for other fora for global governance on food security that go beyond the WTO level, and which have a broader scope than the current Committee on World Food Security (CFS). Fora in which regional trade blocs can meet should be encouraged.

Develop, support and maintain global and regional food-related information systems

Crisis-response mechanisms to deal with uncertainties need to be strengthened by focusing in particular on cooperation in global food-related information systems, linking these to decision-making, and including public goods in food-related information systems. This includes production and trade as well as information on consumption.

Focus on supply-side regulation in trade negotiations, with due consideration of regulatory effects on food security and resource management

Trade regulations are key drivers for economic growth and ensuring food security. Standards, resource management and the internalisation of environmental and social costs should be better integrated in the international dialogue on food production and trade.
KEY MESSAGE 4
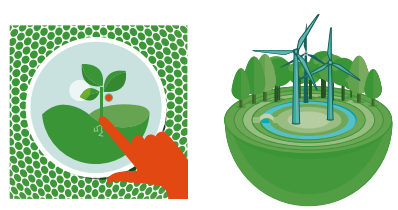

In order to build food security solutions from the ground up, a culture of innovation in food systems should be promoted

\section{Policy recommendations}

Promote innovation that supports diversity

Promote innovation in all determining factors within food systems, including: production, conservation, transport, processing, retailing, access in line with global needs but also attuned to local situations, lifestyle and diversity through new education models and training.

Promote innovation that allows for transitions from the rural to the urban environment

Support initiatives that generate income for the rural poor (e.g. local food value chains) including income integration via off-farm employment, transition to a non-rural environment, and development of rural-urban links for sustainable development (aligning local diets to biodiversity and urban food-provision schemes). 


\section{Concluding remarks}

The purpose of strategic foresight and this exercise was, in fact, to discuss the future of food security in such a way so as to include novel policy concepts and debates which can help prepare decision-makers to plan for uncertainty. Through this foresight process and report, we have aimed to challenge common conventions on food security, while postulating on the complexity and multidimensional nature of the topic under discussion. In this regard, it is crucial to emphasise that our recommendations should be considered rather as areas in which a thorough debate should be opened involving relevant stakeholders.

This report has shown that while food security has long been considered almost exclusively with respect to hunger, malnutrition and humanitarian questions, it is now essential for Europe to move towards an integrated examination of a much broader landscape. Securing 'regular' access to adequate food for the majority of the 8.5 to 9 billion people who will inhabit the earth during 2030-2050, while addressing the food insecurity of a fraction of that total, is how a future European food security policy should be approached.
Europe needs to better exploit the huge opportunity the global food sector represents in terms of innovation, commerce, trade, health, wealth generation and geopolitical relations. To do so, it needs to streamline its various policies addressing one or another aspect of those global food chains. At the same time, Europe will continue to pay special attention to the eradication of hunger and malnutrition through special antipoverty, rural development and food aid actions.

Establishing a multidimensional and cross-policy platform (i.e. inter-DGs) to address the global and interconnected dimensions of food security through a rolling and iterative process is a step in the right direction. Although agriculture and fisheries are fundamental and essential components of the food system, it would be misguided to address the future of food security without looking at the many other determining factors within the system. In line with this, and as an ultimate goal, we can envision the evolution of present-day policies on food security and beyond into a Common Food System Policy in which the systemic and global dimensions of food security are both encompassed in full.

\section{A future of opportunities for food security through innovation}

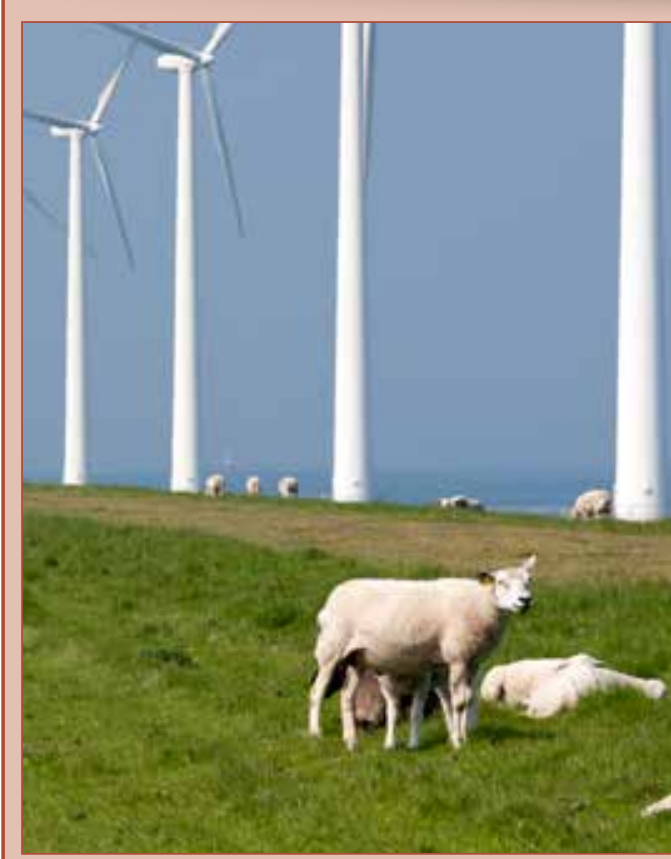

"By 2030, most governments with serious food insecurity problems will invest over $10 \%$ of their expenditure in improving economic, physical and social infrastructures. Overall, the food-production system will be more structured and stable as a consequence of the modernisation of most agricultural systems, with some failures where structural constraints limit implementation of innovative solutions and/or where negative effects of climate change have a significant impact. Both women and men have better access to microfinance and the basic knowledge to improve their farming activities in terms of both overall yield and resilience. Access to agricultural education and training has significantly improved and has contributed to finding answers to sustainable food production problems, implementing solutions, and providing services and opportunities for rural people. Private-sector and local entrepreneurship partnerships have facilitated the training of community members to achieve food security and also to be better integrated into market flows. Aquaculture has spread and profits from the intensive and widespread use of processes and technologies similar to those in agriculture, including selective breeding techniques or specialised feed production. The importance of the external capital is rapidly growing for both agriculture and aquaculture..." 


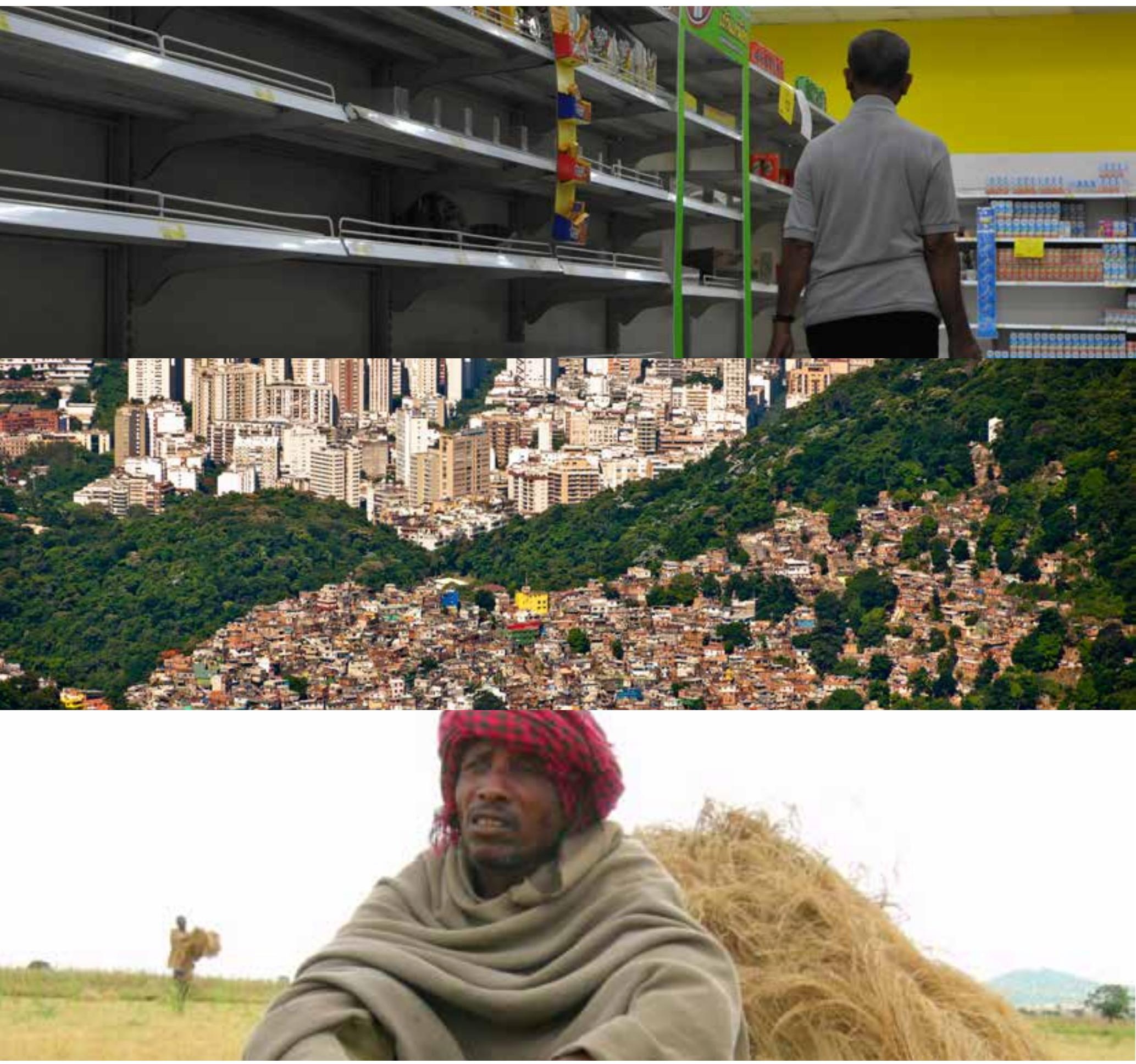




\section{Case Studies}

What would happen if... international trade in agriculture broke down?

What would happen if... the world was hyper-urbanised?

A future of opportunities for food security through innovation 


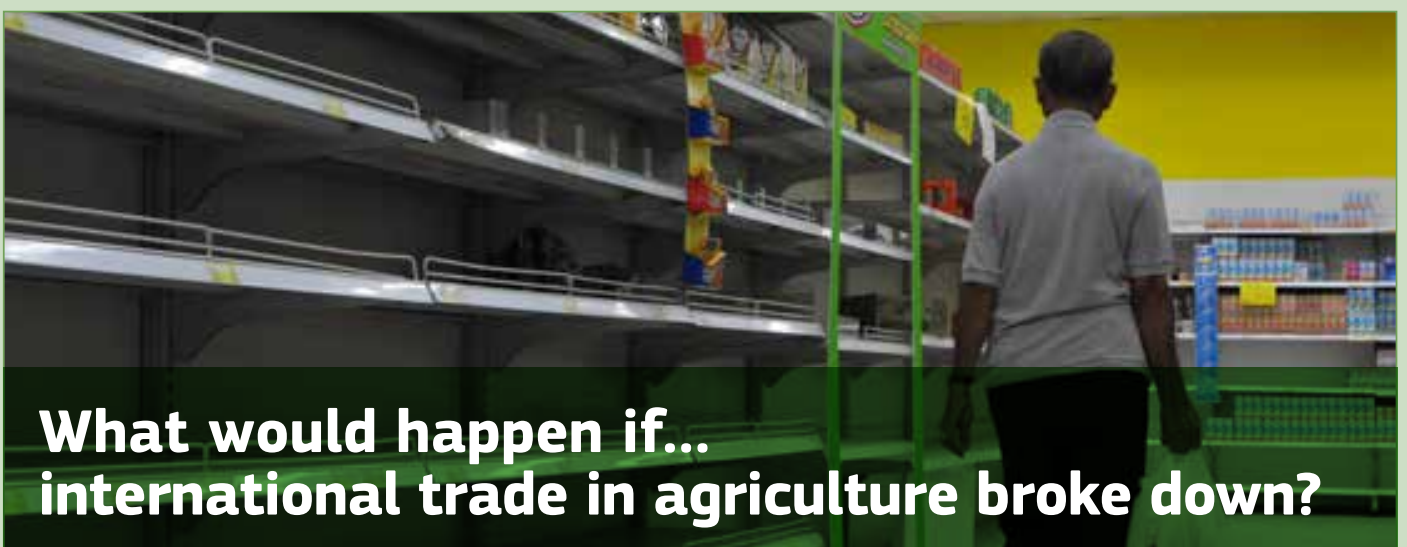

\section{The story continues...}

By 2020, WTO-level negotiations on the Agreement on Agriculture (AoA) had failed to make any progress, when commitments made in Bali in 2013 failed to be upheld.Under increased scrutiny by their populations, many countries took a protectionist turn. Regional-level negotiations on trade and agriculture began to supersede any potential progress at WTO level, resulting in the 160-member club becoming increasingly irrelevant in enforcing multilateral trade rules. By 2030, a series of unilateral reforms from emerging economies and regional trade agreements resulted in the WTO become a mere talking shop.

The domino effect of countries withdrawing support was initially set in motion by the US when, during the debate on the 2023 Farm Bill, both the American public and Congress became increasingly disenchanted with the demands to cut domestic support for their farmers. The decision for Europe was similar, as it became increasingly disinterested in pursuing a global trade deal on agriculture given the lack of progress. Africa soon followed suit, citing ideological reasons. The Uruguay round had not delivered, and mistrust in the agricultural trading system was rife. Faced with a situation in which major world regions were withdrawing their WTO support, Latin America also eventually turned more inwards, despite the clear comparative advantage it once held. Brazil and Argentina had already begun shifting their exports towards fossil fuels, such as oil and shale gas, and as agricultural became less and less profitable, the Latin American region ultimately turned its focus towards domestic concerns. In Asia, two regional blocs led by India and China also withdrew support. For geopolitical reasons, China, and countries like Japan, South Korea, Central Asia and parts of Russia were keen to reduce their dependence on the West - self-sufficiency became a political tool. For India, the process was set in motion in Bali in 2013, when India had forcefully argued for unlimited Amber Box support. Despite continued challenges to India's practices by Pakistan and Thailand, India continued to stand its ground, and eventually stopped negotiating on the AoA.

The WTO's inability to conclude negotiations on the AoA widened the policy arena for national regulation and regional agricultural markets even further. Greater efforts towards regionalisation through agreements and arrangements led to the build-up of regional stocks, guarantee mechanisms, insurance schemes, regional finance and regional R\&D programmes. While food-price volatility was extremely high at the global level, different levels of protection and safety nets at the regional level ensured that countries within certain regional blocs were protected from global fluctuations. Clearly, the mantra for food security had become: "food self-reliance at country level through self-sufficiency of the region".

Initially, net-importing countries struggled to meet their overall nutritional needs without the guarantee provided by free international trade. Diminishing diversity in food choice faced by consumers became a reality for consumers across the globe, forcing them to quickly adapt to regionally produced food products; thus traditional diets and seasonal fruits and vegetables started to become staple food sources.

Yet regions proved able to adapt rapidly and build resilience, particularly since the food supply chain had become more stable and predictable. Price predictability fostered private investments in agriculture, which triggered agricultural transformation in agro-industrial clusters defined according to regional planning strategies in agreement with private stakeholders. Sustainability could now be achieved through much shorter supply chains and less reliance on massive infrastructure and transport needs, particularly significant given the cost of energy and the lower cost-efficiency of cargo shipping which had stimulated food crises in the past. Safety and regulatory standards were adapted according to regional needs and realities, while regional training, research, policy and advocacy networks, and community support were increasingly set up. To summarise, it is only with a rigorous analysis of the new complexity of this regionalised world, and the right sets of policies that regions are able to promote food security. 
For Europe, this came at a high economic cost, initially leading to a drop in income growth due to falling exports and less employment opportunities in the agri-food chain sector. Initially, the effect on large European agri-businesses was dire, until they refocused their business plans towards the Euro-Mediterranean market. Euro-Mediterranean agri-trade has witnessed a dramatic boost in the exchange of fruit and vegetables, largely to the benefit of North African and Near East countries, but quite detrimental to the southern European economies which have never quite recovered from the financial crisis of 2008.

European consumers are able to buy more European products, but at a much higher price. While there is definitely less variety of food products, at least quality - as perceived by consumers - is improving due to rigorous safety standards and shorter value chains. Europeans have become more protective towards their natural resources, reducing their dependence on foreign oil and gas, investing in alternative energies, and leading the fight against climate change.

The US is taking an isolationist stance towards food production and consumption while maintaining its corporate technology-based model. In fact, the US was left with no other choice than to become wholly self-sufficient, turning to the Pacific-American Free Trade Area as the answer to food self-reliance. In most other parts of the US, the continued progress of biotechnologies has allowed production levels to remain fairly consistent. Supermarkets, commoditised food, and long regional supply chains continue to characterise the food system. Overall, the US is experiencing a small reduction in income due to falling exports.

With the loss of income generated from food exports, rich agri-businesses in Latin America have witnessed a significant set-back. Fewer export opportunities affect not only landowners and agri-businesses, but also smallholders and farmers through a loss of predictable income. Inequality is decreasing, as those who made their profits from agricultural exports are losing significant portions of their income. Farmer organisations and grass-root movements are re-establishing the role of smallholder farming and reorientation of the market towards domestic consumption. Linkages between rural and urban areas have been reinstated, and urban agriculture is emerging in major centres across the continent. On the whole, trade in fishery products is declining significantly, leading countries like Peru to shift towards combined rice and fish farming in order to generate income and improve the nutritional prospects for their populations.

An active regional, CAP-style agricultural system is failing to emerge, namely due to its complex heterogeneity, and because there is no need to boost production. Instead, support is going to local farmers and smallholders via safety nets and compensatory measures.

Asia is developing strong regional agricultural policies, with two separate CAP-like systems, led by China and India, respectively. Regional governance has become central to ensuring food security. Investments in productivity are being stepped up to meet the high demand across the continent. However, they are not necessarily focused on sustainability - rather, they are meeting the needs of rural farmers. Investment in agricultural production and a focus on the ability of rural areas to feed the cities implies that the urban poor are not being prioritised. Large groups of urban dwellers are unemployed and hungry, due to inadequate access to the highly priced domestic products that now dominate the market.

With global food-price volatility high, India is managing food prices effectively, while China is attempting to stabilise the situation. Food distribution across the region comes at a cost: food waste is on the rise as the result of an increase in public intervention and food inventories.

In Africa, although growth has slowed across the continent, increased productivity within the agricultural sector has slowly started to reverse this effect. Under the leadership of countries like Nigeria, Ghana, and Zambia, regionalised CAP-like systems are developing, largely funded by rents from natural resources. Land-tenure reforms are under way, transport and communication systems are improving thanks to significant private and public investments, and government support is encouraging farmers to increase production, both in terms of volume and through diversification. Agricultural activity is gradually moving away from cash crops towards non-tradables. The focus on local products is eventually witnessing important shifts in consumer preferences.

The Southern African Development Community (SADC) has immediately put into action the long-awaited plan for a strategic regional grain reserve. By linking the reserves to social safety nets and emergency programmes and boosting production, incomes are starting to rise. The setting up of regional food reserves in other regions, although effective in stabilising prices, is overshadowing social protection schemes and infrastructure development. 


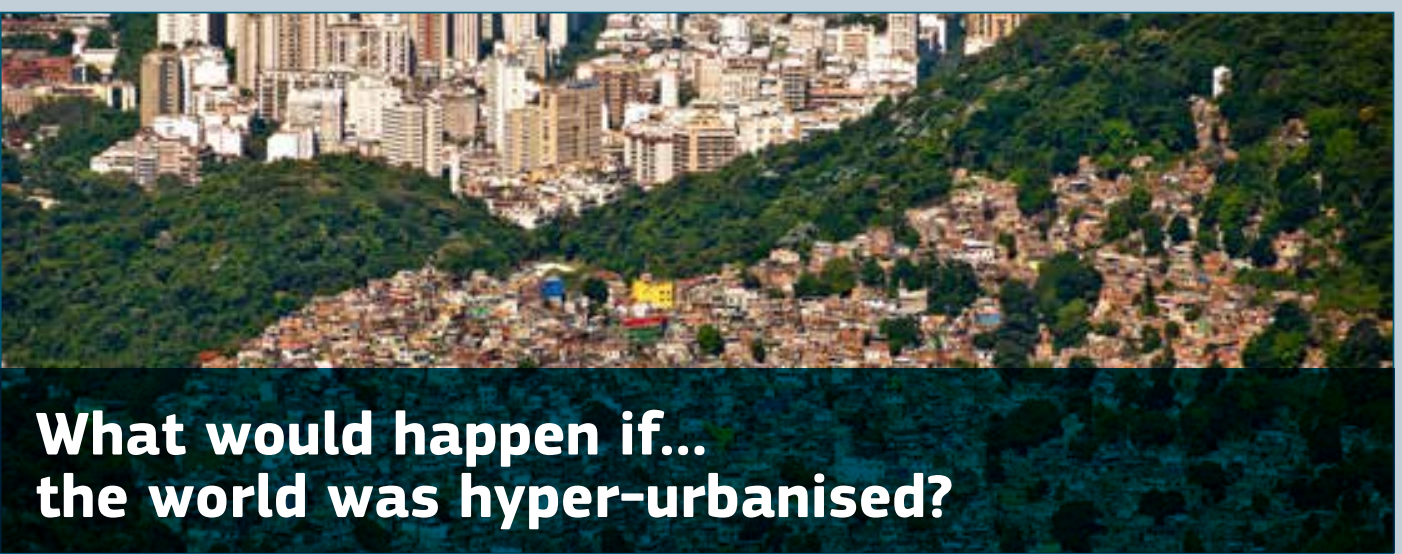

\section{The story continues...}

In principle, overall food production, which increased globally by $50 \%$ between 2005 and 2030, is now sufficient to meet world needs. Developing countries have contributed increasingly to global food availability. In particular, efforts by the international community and national governments to increase agricultural productivity through strong support for smallholders have paid off in regions where yield gaps were easily reduced. The nutritional status of children and women has also improved significantly in African and South Asian rural areas.

However, global food insecurity is still very important while patterns of food insecurity have become more and more scattered. Although the gap between developed and developing countries has been narrowed in terms of food and nutrition security, massive and growing inequalities in access to food have developed at a sub-level, in particular between cities, across cities and within urban and peri-urban neighbourhoods.

\section{The world is now hyper-urbanised}

One of the main causes of the persistent inability of food systems to ensure food security lies mainly in the world's inability to cope with urbanisation in Africa and Asia, which is now higher than was anticipated in the 2010s. This is due to the combined effect of an intensive proactive search for new opportunities and climate-change-driven migration fluxes, which have literally overloaded megacities. Urbanisation in the world has reached $67 \%$, which means there are two urban dwellers per every rural dweller, while projections in the 2010 s forecast a ratio of three to two. Urbanisation in Africa and Asia has reached $55 \%$ and $60 \%$, respectively. More than $85 \%$ of Latin Americans live in urban centres, just like those in industrialised countries. In Africa, some countries are now largely urbanised, such as South Africa (73\%), Nigeria (64\%) and some North African countries (between $75 \%$ and $85 \%$ ).

More importantly, this urban growth -originating mainly from rural-urban migration and the reclassification of rural areas (rurbanisation) - has been accompanied by a drastic change in the patterns of urbanisation itself, which has now put further pressure on food systems, unprepared for the megacities' 'explosion'. The rural-urban migration in Africa and Asia of the 2010s towards all kinds of urban centres (small, medium-sized or megacities) has now been replaced by migration to megalopolises where employment opportunities, advanced medical assistance, educational facilities and services are concentrated and easier to access.

In Africa, Lagos and Cairo now number 23 and 18 million inhabitants, respectively, whereas Johannesburg, Greater Pretoria and East Rand have merged into a conurbation of 18 million inhabitants. As predicted in the 2010s, but with an even larger population now, major megalopolises are also located in Asia: Dhaka, Shenzhen, Karachi, Delhi, Beijing, Guangzhou, Shanghai, Manila, Mumbai, Kolkata, etc. In some countries, since there are still so few domestic job opportunities, international migration remains important even in large cities. Migration is also intra-continental, in particular from remote and landlocked countries (e.g. Central African and Sahel countries) to coastal regions (e.g. Gulf of Guinea and North Africa), but also between cities across borders. Recurrent conflicts and the increased prevalence of natural disasters are still feeding the flow of refugees and internally displaced people, who often end up in urban centres.

There are several reasons for the huge rural-urban and international migration patterns. First, increased agricultural productivity and trade liberalisation has often led - as required - to a virtuous circle of increased export opportunities and the overall economic transformation of rural areas in many developing countries. However, this happened mainly through the enlargement of farms and their consolidation into competitive business entities, which only benefited a relatively small number of farmers. The pressure for increased competitiveness, 
the investments required, and the rigorous safety and quality standards needed to access international markets were just too high for the vast number of smallholders who, consequently, were unable to take advantage of the new opportunities presented by trade liberalisation. Secondly, young generations could not find the amenities and cultural stimuli in rural areas that would motivate them to stay. Large African and Asian cities, with their new and grander lifestyles and higher-standard infrastructures and services, became irresistibly attractive for younger generations eager to live an urban life and to be very closely connected to the global village.

\section{Possible negative impacts on food security}

By 2030, food insecurity in African and South Asian rural areas is no longer a critical issue. The rural population has decreased significantly, and includes fewer but wealthier farmers as well as new agro-industrial workers and entrepreneurs, who have benefited from agricultural transformation and higher international food prices. By 2030, most of the rural poor have moved to the cities and are predominantly food insecure.

This massive and rapid wave of urbanisation towards big cities, the higher levels of international migration and income growth have dramatically intensified the change in food consumption patterns in Africa and Asia, which had already been initiated by trade liberalisation and the expansion of transnational food corporations. Lifestyle changes in the cities, new constraints on non-agricultural workers (e.g. less time for cooking, etc.) and intense marketing by the main international brands have fostered the shift of a large part of the population towards dairy and meat diets, and fast and processed food. A very demanding upper class and a fast-growing middle class have favoured the rise of supermarkets in which all the international brands are now available. There is also a large demand for quality food, fresh perishables, a wide variety of products and all-seasonal supplies. Generally speaking, there is now a large choice of foods in every megacity across the developing countries. In this respect, the global food system has managed to cope with the greater and more diverse demand.

However, food choice and availability in these megacities are not accessible to everyone, either economically or physically. Although economic growth has been a major driver (6\% to $9 \%$ annual growth in many developing countries) it has also resulted in greater inequality due to weak governance and corruption which are widely shared characteristics of these fast-rising megacities. The strong focus on rural development strategies in Africa and South Asia fostered by the international development community, has overshadowed smart urban planning and the proactive internalisation of food security challenges associated with hyper-urbanization. Consequently, the development of new urban neighbourhoods has been chaotic, involving a large part of self-organisation among the newcomers who gather in urban ghettos. These areas, which are populated by the poorest, remain "urban food deserts", i.e. "poor, often informal, urban neighbourhoods characterised by high food insecurity and low dietary diversity, with low levels of household access to food". ${ }^{65}$ Nutritious food is not available in these neighbourhoods as most quality supermarkets or rural markets are inaccessible due to both significant physical distances and expensive food products. Access to quality food remains impossible due to time and price constraints for these households, who rely on casual job opportunities (low-wage, part-time, short-term jobs) and the informal sector. Migrants who have just arrived are particularly vulnerable. The only food access points for these urban lower classes are local, generally informal, food retail shops and street vendors selling cheap processed foods leading to higher-fat, added-sugar and salt-laden diets, and increased health issues linked to over-nutrition (obesity, diabetes, high blood pressure, heart disease, cancer, etc.). When fruits and vegetables are available, they are much more expensive than junk food. Therefore, any food- and nutrition-secure households in these areas need to spend too much of their budget on food, which affects other items (e.g. health, education, etc.).

Overall, the food security challenge has become much more difficult to solve due to the double burden of malnutrition (continued under-nutrition and rising obesity and food-related diseases), making it increasingly a public health issue. Its strong urban dimension has also shifted the focus on to the security part of the equation, rather than the development one. Indeed, those poor urban households who suffer from higher food prices and remain highly vulnerable to food-price volatility and disruptions in food supply (both in highly import-dependent countries and in cities which have inadequately secured their links with their hinterlands) are feeling increasingly insecure within their society. As a result, the underlying conditions for social unrest and political conflict have increased in many megacities in Africa, Asia and Latin America, and some industrialised countries are now experiencing food-related riots. 


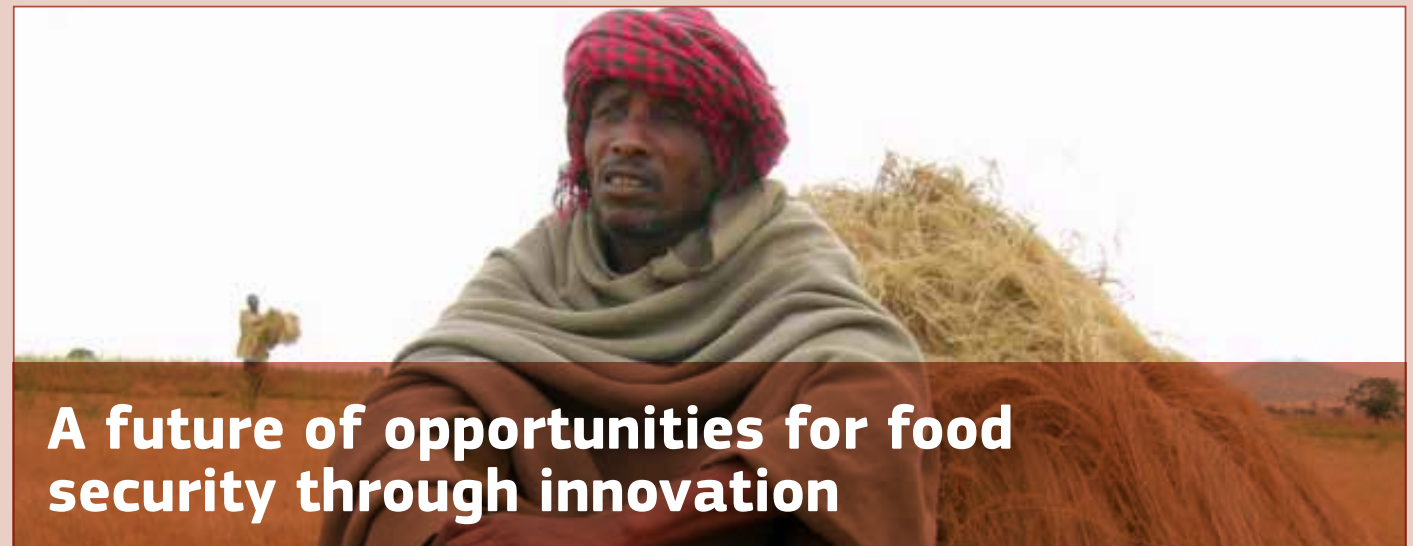

\section{The story continues...}

Better governance of land and water rights has raised confidence among farmers who have been persuaded that hard labour and investments will repay their business, which can better react to climate and market disturbances. Extension services have succeeded fairly well in transferring technologies that best respond to the requirements of specific environment/crop system/aquatic production. In the most successful cases, and where agriculture has shifted from a subsistence function to true business, the entire food-production system has evolved through various forms of entrepreneurship and supply/value chains. Essential in this process has been a new/better interconnection among rural and urban communities (better infrastructures). Rural areas now have a revamped role in responding to the changing needs of the middle class, which is 'exploding' in urban areas. Urbanisation has become an incredible opportunity for rural areas which will have to provide food for 60-70\% of the population who will live in cities. Creating social and economic continuity between rural, semi-rural, urbanised areas and megacities will re-shape the concept of food security from "how to feed the poor" to "how to secure food supply in answering new emerging demand (quantity, quality, type, processing and more).

\section{Not just rural}

When innovation is discussed in the context of food security it is intrinsically linked to farming and how adopting new technologies can increase yield, sustainability and the overall benefits for both farmers and the environment. The rationale behind this is that $65-70 \%$ of the world's poor are estimated to be living in rural areas and in the years to come they will have to feed themselves sustainably, which is an overarching principle that applies to the entire planet. ${ }^{66}$ It is now clear that under adequate conditions, the sustainable intensification of African and Asian agriculture can produce higher yields, generate reasonable income for farmers, regenerate the natural capital and environmental services, and contribute to human development. ${ }^{67}$

However, non-farming earnings, which account for $35 \%$ to $50 \%$ of rural household income across the developing world, have had minor coverage in the food security debate. Considering that poverty (i.e. poor accessibility to food) is the major determining factor in food insecurity, innovations that can boost the rural non-farm sector may have a substantial impact on food security and, in turn, have positive influence on the rural sector. Non-farming activities may range from manual and artisanal work to various forms of employment or entrepreneurship requiring few skills. Moreover, they may also serve as multiple-lane bridges to a broader range of opportunities, including acquisition of new skills that can further develop into new jobs or contribute to shaping value chains that can both give value to agricultural production and generate extra earnings to be reinvested in rural activities.

Even though agriculture remains a fundamental source of income and employment for most rural households, by 2030 the share of non-farming income will increase. ${ }^{68}$ Thus, by 2030, non-farming earnings will enhance the overall resilience of food access. Urbanisation patterns are tightly linked to the expansion of non-rural activities. Urban concentrations and emerging secondary towns (under 500000 people) play an important role since they provide the ground for new opportunities without generating a severe disconnect with the rural environment. In contrast to migration to megacities, which may lead to irreversible urban migration, lock-in and the "urbanisation of poverty", ${ }^{69}$ secondary towns and/or other types of urban concentrations may absorb unskilled and semi-skilled workers in a variety of non-farming activities. Small cities may function as effective transition zones in which easier access to knowledge can create professional profiles that can return to farming with an entrepreneurial or managerial attitude or move to new jobs in urban centres (megacities). Fostering innovation to sustain job diversification (non-rural activities) in rural areas and improving the rural areas' connections to small and/or larger towns will be an important way out of poverty. 
Rural areas, urban concentrations/small towns and megacities in developing countries are extremely dynamic. Here, continuity, exchanges and transitions are all grounds for growth. Poor farmers, unable to keep abreast of agricultural modernisation, will seek better work and living conditions. Low-skilled labour will move from rural areas to small cities in the search for manual, small trade or artisanal jobs to integrate/stabilise the earnings from agricultural activities. Those farms that are more exposed to climate and market threats will look for options that make them less dependent on agriculture and more secure. Extra earnings may generate reinvestment in agricultural activities or create new pathways out of poverty. ${ }^{70}$

Small cities and urban concentrations have seen a flourish of rural non-farming economies that have developed from informal schemes. The type and level of informality vary according to different production methods and services through entrepreneurship in manufacturing, commerce and services, or as employment in these expanding sectors. Knowledge and skills have improved more through an informal learning process than through formal education, the latter being much more accessible in urbanised areas than in remote rural environments. Artisans with specific expertise and operating informally are involved in formal activities through various types of partnerships (formal and informal). In terms of GDP, the size of the informal sector, including both agricultural and non-agricultural activities, is fast moving and has reached and exceeded the formal public or private sector, which is unable to provide enough jobs for its expanding labour force. Creativity and a good understanding of the needs that call for solutions (delivered through new jobs) are the true innovation engines in the self-employment sector. The informal sector plays an important role in generating income and wealth. The link to the rural environment is still there and could become an important driver in this process.

\section{From small cities to megacities}

Small urban concentrations also facilitate access to education and the acquisition of higher skills. Urban centres are also better connected to global businesses that may or may not be in the agricultural sector. Governments have created education systems able to capitalise on a global wireless environment. ${ }^{11}$ Higher education (codified more than tacit knowledge) has prepared younger generations to perform their jobs more efficiently, to propose solutions and to expand their businesses. In addition, the foundations for self-learning in place provide greater access to opportunities for all. Different business models develop, especially in the service sector. Africa and remote regions of Asia are connected to the rest of the world and new links are created within global businesses. A true shift to the middle class is taking place. Innovation hubs and universities work as real incubators of ideas and create links to global innovation think-thanks. Remote communities that were previously disconnected from the global system are now exporters of innovation. New industries based on local culture, such as the music and film industries, traditional products and more are taking off and are continuously creating new employment opportunities. The transition from small urban centres to megacities is stimulated by both the desire for a better life and an intellectual stimulus (the Cheetah Generation). The rural environment is a distant memory

\section{From megacities to global business}

Creativity and special skills move freely in the global job market. Young generations may choose to move to new enabling environments (different cities, nations or continents) that facilitate the expression of their potential or work to improve the environment in which they live. If they stay, young people will become agents for national political reform, based on an understanding of sustainable developmental patterns and the consequences of specific choices. Small producers (in both rural and non-rural communities) can take advantage of independent entrepreneurship and/or collaborations with other investors in order to be involved in the system and become part of value chains that develop into new profitable business models. Business becomes global. The rural environment no longer acts as a physical, social and intellectual constraint.

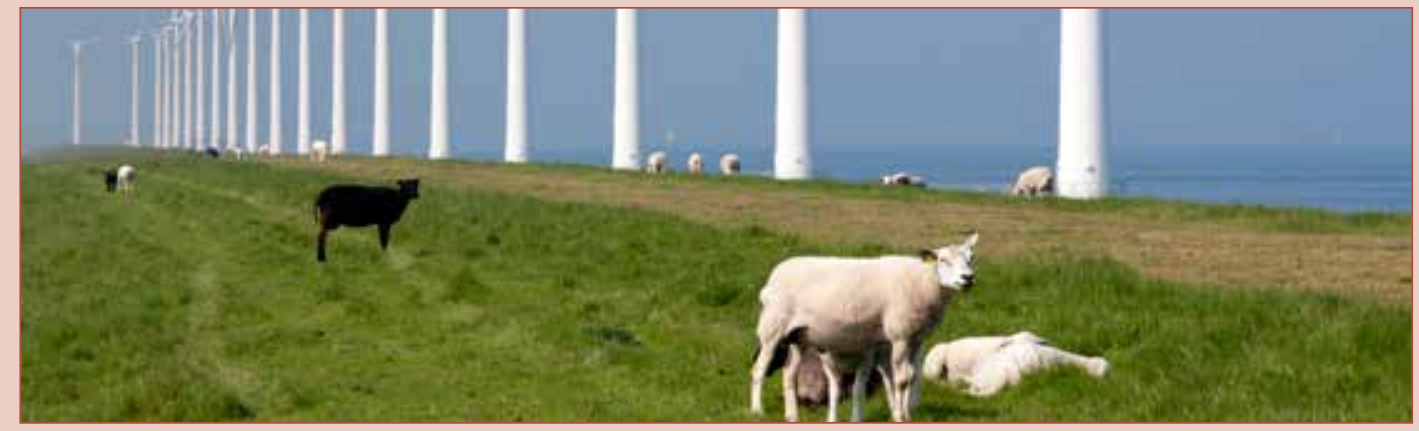




\section{Endnotes}

1. Food and Agricultural Organization (FAO), 2009, Final Declaration of the World Summit on Food Security, Rome. www.fao.org/fileadmin/templates/wsfs/Summit/ Docs/Final_Declaration/WSFS09_Declaration.pdf

2. FAO, 1996, Rome Declaration on World Food Security, www.fao.org/docrep/003/w3613e/w3613e00.htm

3. United Nations, Millennium Development Goals, www.un.org/millenniumgoals

4. Spielman, D.J. and Pandya-Lorch, R., 2009, Millions Fed, International Food Policy Research Institute (IFPRI), Washington DC.

5. FAO, 2014, The State of Food Insecurity in the World Rome, www.fao.org/3/a-i4030e.pdf

6. Wheeler, T. and Von Braun J., 2013, "Climate Change Impacts on Global Food Security", Science 341: 508-513.

7. FAO, 2009, How to Feed the World in 2050, Rome, www.fao.org/fileadmin/templates/wsfs/docs/expert paper/How_to_Feed_the_World_in_2050.pdf

8. Fereres, E. et al., 2011, "Reflections on food security under water scarcity”, Journal of Experimental Botany 62, 12: 4079-4086

9. Tilman, D. et al., 2002, "Agricultural Sustainability and intensive production practices", Nature 418: 671-677.

10. Kearney, J., 2010, "Food consumption trends and drivers", Philosophical Transactions of the Royal Society B: Biological Sciences 365: 2793-2807.

11. Zomers, A., 2014, "Remote access: Context, challenges, and obstacles in rural electrification", IEEE Power and Energy Magazine, 12, 4: 26-34.

12. Munyeche et al., 2011, "Linking small-scale African growers to value markets: Development of a co-owned produce marketing organisation as the standards holder", Acta Horticulturae 895: 185-192.

13. Oppong, J. et al., 2014, "The global health threat of African urban slums: The example of urban tuberculosis", African Geographical Review.

14. Royal Society, 2009, Reaping the Benefits: Science and the Sustainable Intensification of Global Agriculture. London.

15. UK Government Office for Science - Foresight, 2014 Foresight and African agriculture: innovations and policy opportunities, London, UK.
16. Juma, C., Tabo, R., Wilson, K., Conway, G., 2013 , "Innovation for Sustainable Intensification in Africa", Montpellier Panel Briefing; OECD, 2013, Global Food Security: Challenges for the Food and Agricultural System, Paris.

17. DG DEVCO, http://ec.europa.eu/europeaid/index_en.htm

18. Conway, G., 2012, One billion hungry: Can we feed the world?, Cornell University Press.

19. Spielman, D.J. and Pandya-Lorch, R., 2009.

20. Sonnino et al., 2014, "'Sustainable food security: An emerging research and policy agenda," ", International Journal of Sociology of Agriculture and Food. 21, 1: $173-188$.

21. UK Foresight, 2011.

22. Paillard, S., Treyer, S. and Borin, B., 2010, Agrimonde. Scenarios and Challenges for Feeding the World in 2050, collection Editions Quae.

23. European Commission - Standing Committee on Agricultural Research (SCAR), 2011, Sustainable food consumption and production in a resource-constrained world, Brussels.

24. Netherlands Scientific Council for Government Policy (WRR), 1992, Ground for choices: four perspectives for the rural areas in the European Community, Sdu Uitgevers, The Hague.

25. United Nations Environment Programme, 2002, Global Environment Outlook 3: Past, present, and future perspectives.

26. Schroeter, D., Cramer, W. et al., 2004, ATEAM - Advanced Terrestrial Ecosystem Analysis and Modelling, Final Report, Potsdam Institut für Klimafolgenforschung.

27. Millennium Ecosystem Assessment, 2006, Ecosystems and human well-being: Scenarios - Findings of the Scenarios Working Group, Millennium Ecosystem Assessment, Island Press, Washington DC.

28. EUruralis, 2006, EUruralis project, www.eururalis.n

29. European Environment Agency, 2006, PRELUDE Prospective Environmental Analysis of Land Use Developments in Europe.

30. EC-SCAR, 2008, FFRAF Report: Foresighting food, rural and agri-futures, Brussels.

31. European Science Foundation, 2009, European Food Systems in a Changing World, Strasbourg.

32. Fereres et al., 2011. 
33. Gerland et al., 2014, "World population stabilization unlikely this century", Science 346, 6206: 234-237.

34. Ibid.

35. Ibid.

36. UK Foresight, 2011

37. Ibid.

38. Von Braun, J. et al., 2005, New Risks and Opportunities for Food Security, IFPRI, Washington DC.

39. Ray, D.K. et al., 2013, "Yield Trends Are Insufficient to Double Global Crop Production by 2050", PLOS ONE 8, 6: e66428.

40. UK Foresight, 2011.

41. FAO, 2009, Global Agriculture towards 2010, Rome.

42. Bennett, D. and Jennings, R., 2013, Successful Agricultural Innovation in Emerging Economies: New Genetic Technologies for Global Food Production, Cambridge University Press, Cambridge.

43. FAO, 2012, World agriculture towards 2030/2050, The 2012 Revision, Rome.

44. Pimentel, D. and Burgess, M., 2013, "Soil Erosion Threatens Food Production", Agriculture 3: 443-463.

45. Tanji, K.K., 1990, "Agricultural salinity assessment and management", ASCE manuals and reports on engineering practice No. 71, American Society of Civil Engineers, New York.

46. Läuchli, A. and Grattan, S.R., 2007, "Plant Growth and Development under Salinity Stress", in Jenks et al., eds. Advances in Molecular Breeding Toward Drought, and Salt Tolerant Crops, Springer: 1-32.

47. Cattivelli, L. et al., 2008, "Drought tolerance improvement in crop plants: an integrated view from breeding to genomics", Field Crops Research 105: 1-14.

48. Pardo, J.M., 2010, "Biotechnology of water and salinity stress tolerance", Current Opinion in Biotechnology 21, 2: 185-96.

49. Lisk, F., 2013, “'Land grabbing' or harnessing of development potential in agriculture? East Asia's landbased investments in Africa", Pacific Review 26, 5: 563587; Rulli, C., D'Odorico, P., 2014, “Food appropriation through large scale land acquisitions", Environmental Research Letters 9, 6, Article no. 064030.

50. FAO, 2012, World agriculture towards $2030 / 2050$, The 2012 Revision, Rome

51. IFPRI, 2013, 2012 Global Food Policy Report, IFPRI, Washington DC

52. Rosegrant, M.W. et al., 2008, Exploring alternative futures for agricultural knowledge, science and technology, ACIAR Project Report ADP/2004/045, IFPRI, Washington DC

53. Desmet, K. and Rossi-Hansberg, E., 2012, On the spatial economic impact of global warming, Princeton University Press; Marchiori, L., Maystadt, J.-F. and Schumacher, I., 2012, "The Impact of Weather Anomalies on Migration in Sub-Saharan Africa", Journal of Environmental Economics and Management 63, 3: 355-374
54. Swinnen, J., 2011, "The Right Price of Food", Development Policy Review 29, 6: 667-688.

55. COM(2009)163, Green Paper - Reform of the Common Fisheries Policy.

56. World Bank, 2013, Fish to 2030: Prospects for fisheries and aquaculture, Agriculture and Environmental Services Discussion Paper 3, Report no. 83177.

57. Hall, S. et al., 2011, Blue Frontiers: Managing the environmental costs of aquaculture, The WorldFish Center, Penang, Malaysia; Ellingsen, $\mathrm{H}$. and Aanondsen, S., 2006, "Environmental impacts of wild caught cod and farmed salmon - a comparison with chicken", International Journal of Life Cycle Assessment 1, 1: 60-65.

58. COM(2010) 127, An EU policy framework to assist developing countries in addressing food security challenges and Council Conclusions on EU policy framework to assist developing countries in addressing food security challenges, 10 May 2010.

59. $\operatorname{COM}(2013) 141$, Enhancing Maternal and Child Nutrition in External Assistance: an EU Policy Framework.

60. $\operatorname{COM}(2012) 586$, The EU approach to resilience: learning from food security crises.

61. Godfray et al., 2010, "Food security: The challenge of feeding 9 billion people", Science 327: 812-818.

62. United Nations Human Settlement Programme, State of the World's Cities 2012/2013, Prosperity of cities.

63. Satterthwaite, D., McGranahan, G., Tacoli, C., 2010, "Urbanization and its implications for food and farming", Philosophical Transactions of the Royal Society B: Biological Sciences 365: 2809-2820; Battersby, J. and Crush, J., 2014, "Africa's Urban Food Deserts", Urban Forum 25, 2: 143-151.

64. Christiaensen L. and Todo Y, 2014, "Poverty Reduction During the Rural-Urban Transformation - The Role of the Missing Middle", World Development 63: 43-58.

65. Battersby, J. and Crush, J., 2014.

66. World Bank, 2008, World Development Report 2008: Agriculture for Development, Washington DC, http://siteresources.worldbank.org/INTWDR2008/ Resources/WDR_00_book.pdf

67. UK Foresight, 2011.

68. Davis, B. et al., 2010, "A Cross-Country Comparison of Rural Income Generating Activities", World Development 38, 1: 48-63.

69. Christiaensen L. and Todo Y, 2014

70. Fritzsch, J., 2012, "Is non-farm income diversification a feasible option for small-scale farmers? An assessment using a composite fuzzy indicator", PostCommunist Economies 24, 3: 403-417; Li, Z.G., 2014, "Analysis of economic effect of rural labor transfer in central region", Advanced Materials Research 926-930: 3746-3749.

71. Elahi, S., De Beer, J. et al., 2013, Knowledge and Innovation in Africa: Scenarios for the Future, Open A.I.R Network. www.openair.org.za/images/KnowledgeInnovation-Africa-Scenarios-for-Future.pdf 
Europe Direct is a service to help you find answers to your questions about the European Union

Freephone number $(*)$ : 0080067891011

${ }^{*}$ ) Certain mobile telephone operators do not allow access to 00800 numbers or these calls may be billed.

A great deal of additional information on the European Union is available on the Internet.

It can be accessed through the Europa server http://europa.eu.

\section{How to obtain EU publications}

Our publications are available from EU Bookshop (http://bookshop.europa.eu),

where you can place an order with the sales agent of your choice.

The Publications Office has a worldwide network of sales agents.

You can obtain their contact details by sending a fax to (352) 29 29-42758.

\section{European Commission}

\section{EUR 27252 EN - Joint Research Centre - Foresight and Behavioural Insights Unit}

Title: Global Food Security 2030: Assessing trends with a view to guiding future EU policies Authors: Albino Maggio, Tine Van Criekinge, Jean Paul Malingreau

Luxembourg: Publications Office of the European Union

$2015-41$ pp. $-21.0 \times 29.7 \mathrm{~cm}$

EUR - Scientific and Technical Research series - ISSN 1831-9424 (online), ISSN 1018-5593 (print)

ISBN 978-92-79-48364-6 (pdf)

ISBN 978-92-79-48365-3 (print) 


\section{JRC Mission}

As the Commission's in-house science service, the Joint Research Centre's mission is to provide EU policies with independent, evidence-based scientific and technical support throughout the whole policy cycle.

Working in close cooperation with policy Directorates-General, the JRC addresses key societal challenges while stimulating innovation through developing new methods, tools and standards, and sharing its know-how with the Member States, the scientific community and international partners.

\section{Serving society Stimulating innovation Supporting legislation}

JRC Science Hub: https://ec.europa.eu/jrc 